\title{
DE LA NATURALEZA \\ A LA REPRESENTACIÓN. \\ CIENCIA EN LOS ANDES MERIDIONALES ${ }^{1}$
}

\author{
Rafael Sagredo Baeza \\ Pontificia Universidad Católica de Chile
}

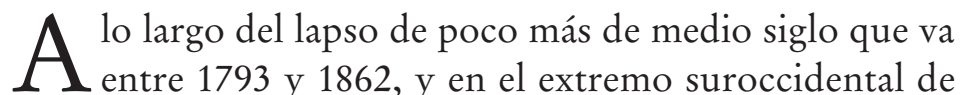
América del Sur, la cordillera de los Andes fue motivo de numerosas y heterogéneas descripciones, observaciones, mediciones y exploraciones destinadas a satisfacer los intereses de imperios, gobiernos, naturalistas, viajeros, científicos, geógrafos y aventureros, entre otros, de una gran variedad de actores y personas que por sus actividades o necesidades hicieron del fenómeno natural objeto de su preocupación y estudio.

Entre quienes exploraron los Andes, científicos como Alejandro Malaspina, José Espinoza, Felipe Bauzá,

Fecha de recepción: $1^{\circ}$ de diciembre de 2016

Fecha de aceptación: 28 de febrero de 2017

\footnotetext{
${ }_{1}^{1}$ Preparado en el contexto del proyecto FONDECYT No 1130515, "Los hombres de los límites. La delimitación y demarcación de la frontera chileno-argentina. 1881-1908”.
} 
Alexander von Humboldt, Charles Darwin, Claude Gay, Ignacio Domeyko, Amado Pissis, Martin de Moussy, Germán Burmeister, James Gilliss y Rodulfo Philippi, con sus descripciones, representaciones y mediciones a diferentes escalas y por heterogéneos intereses, ofrecen una posibilidad hasta ahora poco aprovechada de ilustrar y explicar algunos de los temas y problemas propios de la historia social de la ciencia, como lo son las prácticas de quienes cultivan el saber, la forma en que lo hacen, los instrumentos y técnicas que utilizan, los objetivos que los motivan, los resultados de sus afanes y el uso social que de sus exploraciones, investigaciones, datos, cifras, descripciones y deducciones hicieron los más diversos actores; por ejemplo, los poderes políticos o las comunidades científicas que no sólo promovieron la exploración científica sino que, sobre todo, utilizaron el conocimiento acumulado sobre los Andes meridionales.

El trabajo de los exploradores y naturalistas comisionados por los imperios, sobre todo el español y el inglés, a lo largo del siglo xviII y primeras décadas del xix; así como el de los geógrafos, naturalistas, botánicos y expertos en minería al servicio de los estados nacionales surgidos luego de la independencia, que hacia mediados de la centuria fueron utilizados como referencia por científicos con preocupaciones globales, son las fuentes de un trabajo que, además de ejemplificar la práctica científica en y sobre los Andes, mostrará la evolución de las representaciones sobre la cordillera que su continuo reconocimiento hizo posible. Por ejemplo: de ruta imperial y por lo tanto instrumento de comunicación, a deslinde natural y por ello elemento de separación; de paisaje apto para la contemplación, a objeto de medición y examen; de forma del relieve uniforme, a orografía hete- 
rogénea y multiforme; de cordillera singular, a cordillera plural; de Andes argentino-chilenos a cordillera de Chile y cordillera de Argentina; de objeto de representación cartográfica, a motivo de descripción textual; de forma del relieve local y regional, a orografía planetaria; de realidad natural, a abstracción científica. Todo en el lapso de poco más de medio siglo, con distintos ritmos, significados y efectos, pero siempre reflejando el contexto social, político y cultural, los usos y prácticas, los intereses y objetivos existentes en la época, en la coyuntura, el momento - fuera global, nacional o multinacional - en que los hombres de ciencia transitan, contemplan, exploran o estudian los Andes y definen la geografía del planeta. Por último, también buscamos señalar que el aparataje mecánico, el instrumental científico, un marco conceptual y teórico, el uso de las más modernas tecnologías de cada época para medir, definir y delinear la realidad natural, no garantizan que las consecuencias de su aplicación a una forma del relieve concreta, como los Andes, ofrezca resultados uniformes o, incluso, evite las controversias sobre el significado de los datos obtenidos, y con ellos, sobre la definición de la naturaleza examinada.

Procesos que demuestran, mediante las descripciones de los Andes, que en definitiva las formas geográficas son medios para ilustrar el saber, consecuencia de una época, de intereses concretos, sean científicos o políticos; que la aproximación científica a los Andes meridionales no es uniforme y menos todavía unívoca; que la naturaleza tendrá la forma que la ciencia delinee y, por último, que puede haber tantas representaciones de un fenómeno natural como perspectivas de análisis se apliquen a su comprensión. 
A fines del siglo xvinI, cuando el tráfico de bienes y personas entre el virreinato del Río de la Plata y la gobernación de Chile se intensificó como consecuencia de las reformas borbónicas, el contrabando y en general los estímulos propios del desenvolvimiento económico y comercial, la cordillera de los Andes, y en particular el paso que permitía transitar entre el Pacífico y el Atlántico por el eje que une Valparaíso y Buenos Aires por el camino de Portillo, se transformó en un objeto indispensable de conocer, describir y representar.

En su afán por servir los objetivos de la corona española, para los integrantes de la expedición Malaspina el reconocimiento de esta sección tuvo un interés particular, que también se expresó tanto en las ilustraciones que ejecutaron en medio de la montaña como en la cartografía que delinearon del camino cordillerano y de las formas del relieve andinas que cruzaron. Tal vez es la ponderación que José Espinoza y Felipe Bauzá hicieron en la relación de su viaje de Santiago a Mendoza, donde escribieron que el pasaje de tránsito entre las dos colonias era "el más frecuentado de todos los que van al otro lado de la cordillera”, lo que explica la existencia de representaciones tan detalladas y minuciosas de la ruta que, en la vertiente occidental, en Chile, se inicia en el valle de Aconcagua.

Un tramo indispensable de apreciar y cartografiar, compuesto por una sucesión paralela de cordones montañosos en disposición norte-sur, que los científicos ilustraron por medio de distintas vistas de paisajes y formas, pero sobre todo representaron fielmente en lo que a su estructura orográfica fundamental se refiere en el que llamaron "Plano del 


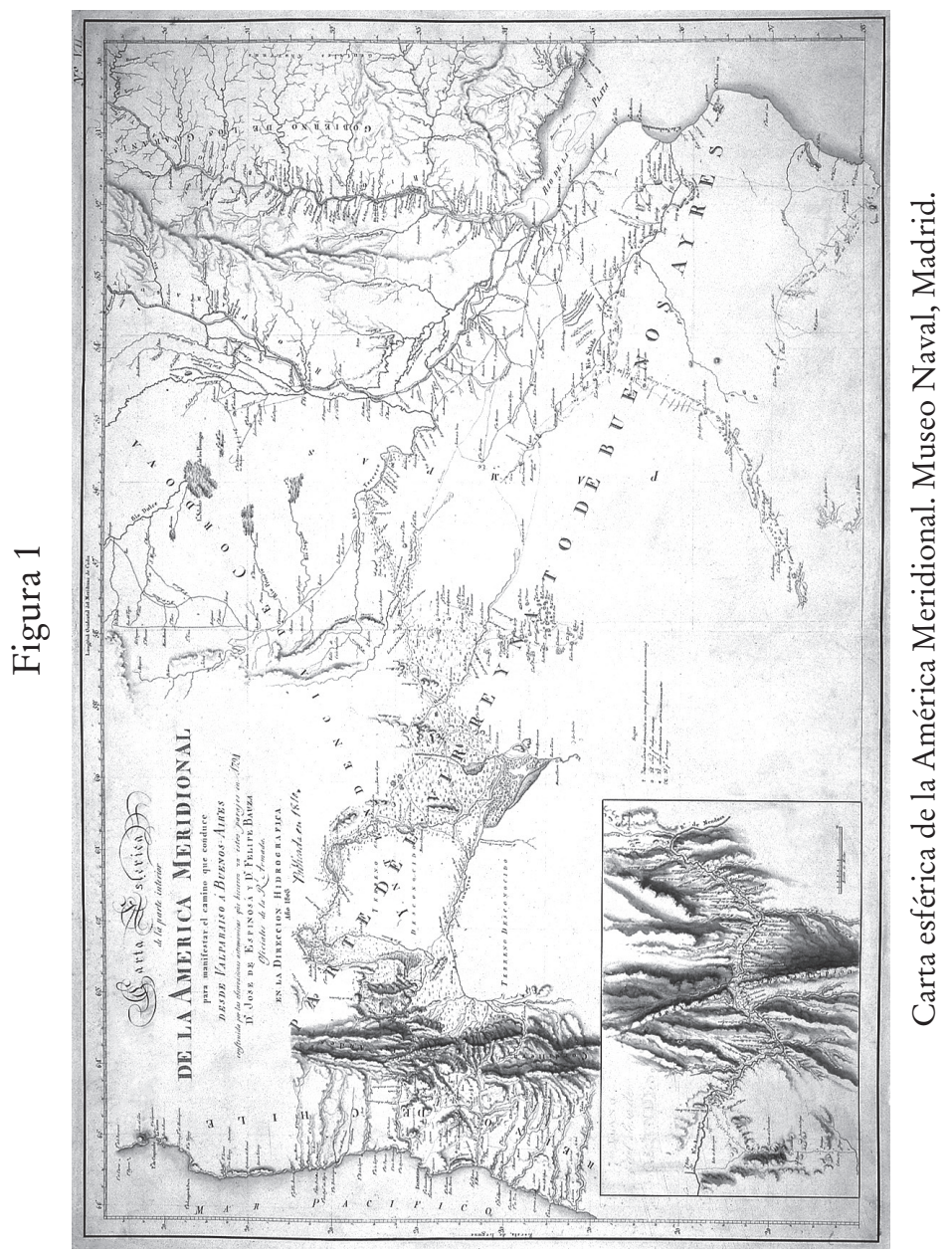


paso de los Andes". Mapa particular que, prescindiendo de su título, también forma parte de la "Carta esférica de la parte interior de la América Meridional para manifestar el camino que conduce desde Valparaíso a Buenos Aires construido por las observaciones astronómicas que hicieron en esos parajes en 1794 José Espinoza y Felipe Bauzá, oficiales de la Real Armada", a escala 1:1 800000 aproximadamente. Una muestra evidente de que para los comisionados ilustrados el reconocimiento de la cordillera, en una perspectiva imperial, fue sobre todo la exploración y evaluación de las rutas más adecuadas para el tránsito y comercio entre Chile y el Río de la Plata, en un esfuerzo por mostrar las posibilidades de comunicación de la, para un criollo del Chile de la época, "famosa cordillera de los Andes que lo divide del virreinato de Buenos Aires". ${ }^{2}$ Contrapunto que refleja una concepción de la territorialidad chilena y sus límites de antigua data entre los habitantes de la entonces colonia, la que a fines del siglo XIX tuvo una consagración política por medio del tratado de límites chileno argentino de 1881, pero que en 1793 los españoles parecían obviar en su afán de aprovechar las posibilidades de intercambio comercial entre las posesiones del imperio.

2 La frase en el texto que con el título de "Una breve idea de Chile" Juan José de Santa Cruz hizo llegar al comandante Malaspina, en SAGREdo Baeza y González Leiva, La Expedición Malaspina, p. 485. Un estudio, en la perspectiva de la historia de la cultura, sobre los Andes y el proceso de asociación con Chile en el siglo xvi como parte de la construcción de identidad territorial, en la estimulante y documentada obra de Alejandra Vega. En ella concluye: "En las postrimerías del siglo xvi la progresiva asociación entre Chile y cordillera terminó por difundir una imagen de esta gobernación que limitaba en la llamada gran cordillera nevada”. Véase Vega, Los Andes y el territorio de Chile, p. 293. 
Así lo refleja no sólo el relato que Espinoza y Bauzá escribieron de su travesía andina, en el que describen con detalle los accidentes del camino, ponderando los desafíos que imponían al viajero; también, el que otro integrante de la comisión ilustrada, el botánico Luis Neé, intentara, pese a los obstáculos, llegar hasta los pasos cordilleranos, y que una vez en el existente casi $200 \mathrm{~km}$ al sur de Santiago, a la altura de la ciudad de Curicó, escribiera ponderándolo por la facilidad que ofrecía el trayecto desde Curicó y sobre todo porque "abreviaría mucho el paso para Mendoza y Buenos Aires". 3

Para Espinoza y Bauzá la ruta que cruzaron, además de "ser sumamente larga, era tan fragosa, estrecha y arriesgada, que sólo la necesidad urgente puede obligar a emprenderlo". Y como lo que les interesaba era dar con "caminos fáciles, cómodos y seguros”, que son los que en su opinión "influyen en la prosperidad de las provincias", con el espíritu práctico y utilitarista propio de la Ilustración de la que eran hijos, ni siquiera se conmovieron con el paisaje cordillerano, pues escribieron que, en medio de la cordillera, "aun la vista no encuentra objeto que la complazca en aquella dilatada extensión”. Entre otras razones porque "todo el camino está acompañado de fragosas y elevadísimas montañas que representan masas enormes de nieve, horrorosos precipicios y tristes recuerdos de desgracias acaecidas". ${ }^{4}$

${ }^{3}$ Véase su escrito "Diario de viaje desde Talcahuano hasta Santiago de Chile", en Sagredo Baeza y González Leiva, La Expedición Malaspina, p. 857.

${ }^{4}$ Véase la relación que escribieron, llamada "Viaje de Santiago a Mendoza y noticias de esta última ciudad", en Sagredo Baeza y González LeIva, La Expedición Malaspina, pp. 875-883. La relación forma parte 
La relación de lo que consideraron "peligroso tránsito" está fundada en las descripciones y menciones de un camino que corre entre "cerros escabrosos y muy pendientes", lleno de quebradas, elevadas montañas, "mucha nieve", grandes cuestas, serranías altas, "infinitos ramales", "mal piso y pedregoso", lleno de derrumbes y cuestas, además compuesto de "un terreno poco firme". Prueba de sus impresiones, escribieron, era la lámina de la "Casa en la cumbre", la que "manifiesta suficientemente lo quebrado, árido y espantoso de aquel terreno". 5

Todo lo anterior no les impidió sin embargo, en su condición de hombres de ciencia, realizar durante su travesía "observaciones barométricas" en las que, concluyeron, eran "montañas sumamente quebradas, estériles y llenas de nieve", y medir el "ancho de la cordillera por la parte de Santiago, contando los rodeos que obliga a hacer su fragosidad", el que calcularon en 50 leguas, es decir, $241 \mathrm{~km}$ aproximadamente, mientras que por el camino que transitaron creyeron haber alcanzado una altitud máxima de cerca de 4000 metros.

Ni siquiera la cumbre de los Andes, con la panorámica que ésta ofrece, conmovió a los científicos, pues ahí lo único que asentaron fue que "desde luego se ve ya al otro lado de la cordillera, o su falda Este; su vista es mucho más horrorosa que ninguna de las precedentes, las montañas son también más negras, están más cargadas de nieve y, finalmente, se ven rodeadas de mayores precipicios”.

del original, nombrado “Descripción del Perú, Buenos Aires, etc...”, manuscrito núm. 17.592 de la British Library.

5 Espinoza y Bauzá, "Viaje de Santiago a Mendoza y noticias de esta última ciudad”, pp. 880-881. 


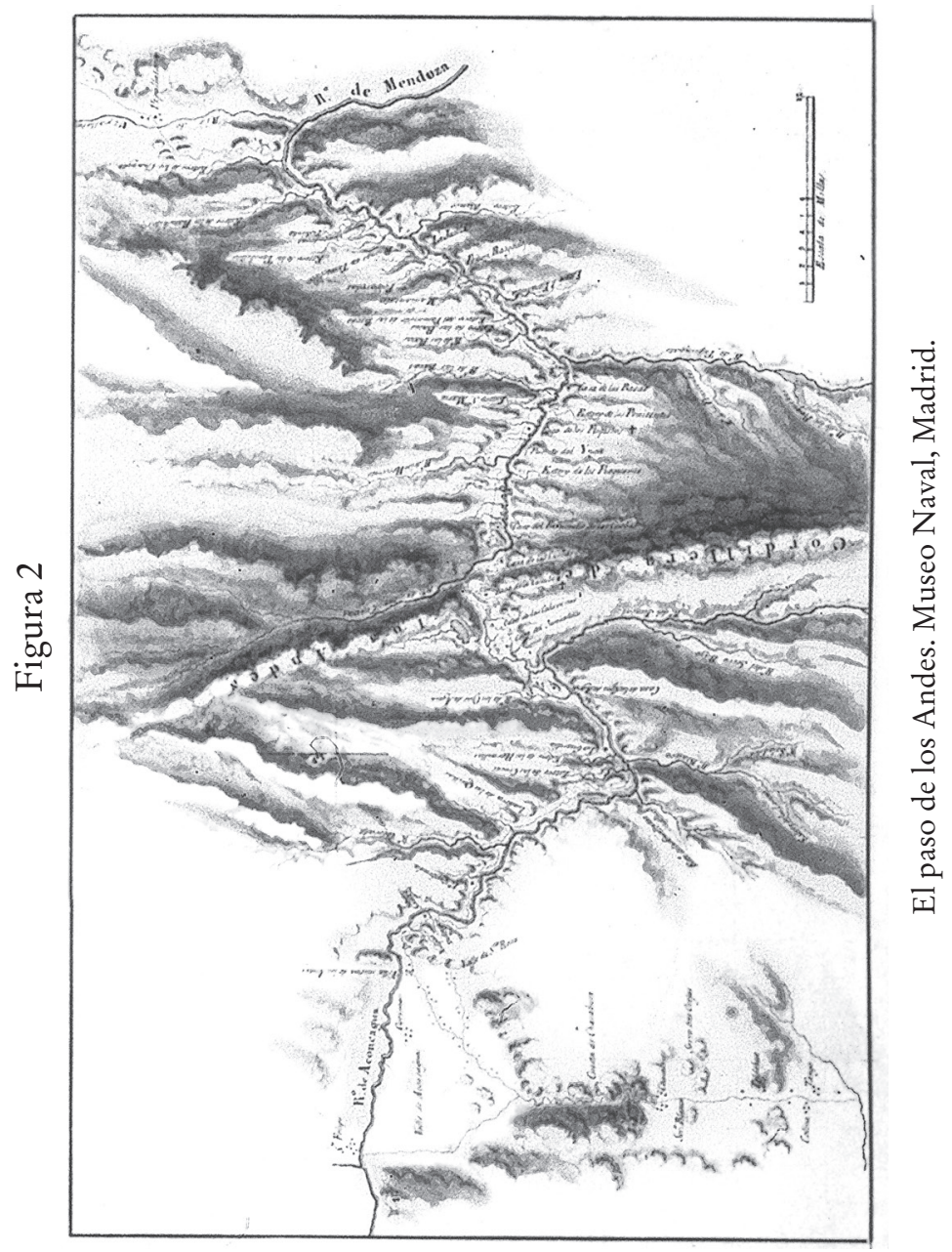


Reflejo de lo que apreciaron en terreno debe considerarse la representación que ofrece el "Plano del paso de los Andes”, preparado a una escala de 1:1500000 aproximadamente. Un mapa de carácter topográfico en el que delinearon el camino que cruzaba la cordillera de los Andes, uniendo su vertiente occidental con la oriental, ruta que graficaron mediante una línea de puntos, y en el que también se muestran los cursos del río Aconcagua, en la vertiente occidental, y Mendoza en la oriental. La representación del relieve es de gran nivel en lo relativo a su diseño y precisión, y sigue la técnica del achurado, con trazos que a medida que se van oscureciendo van representando mayor pendiente, utilizada de forma tal que hace evidente la disposición de los cordones andinos, todos surcados por cursos de agua y afluentes de los ríos principales. La técnica para mostrar el relieve, como la hidrología, los caminos y los poblados, refleja las cualidades de sus autores, científicos ilustrados, cuyas mediciones, cartografía y descripciones ofrecen un gran nivel de exactitud, sobre todo en lo relacionado con la longitud y la latitud.

La pretensión de rigor de Espinoza y Bauzá, como sus trabajos e intereses, quedó expresada en múltiples documentos, entre ellos la memoria publicada en 1809 con el título de "Observaciones de la velocidad del sonido, de latitud, longitud y variación hechas en Santiago de Chile por el Teniente de Navío Don Josef de Espinoza y el Alférez de Navío don Felipe Bauzá en abril de 1794”. En ella asentaron que las observaciones sobre el sonido las hicieron por mera afición y con motivo de haberse trasladado de Valparaíso a Buenos Aires por tierra para alcanzar a las corbetas Descubierta y Atrevida, que transportaban a la expedición 
Malaspina, de la cual formaban parte. Entonces escribieron que "practicamos en nuestro viaje muchas operaciones geodésicas, y adquirimos varios planos, descripciones y noticias geográficas, que, corregidos con aquellas latitudes y longitudes observadas, han servido para formar una carta particular de la cordillera y las pampas". En sus trabajos asentaron que en medio de la cordillera, entonces transformada en campo de experimentación y práctica de la ciencia, realizaron "observaciones de alturas del barómetro, de longitud y variación de la aguja, mediciones con el termómetro de Farenheit y mediciones de altitud". ${ }^{6}$

Aunque conscientes de que sus observaciones no eran de "una exactitud suma", afirmaron que "merecían confianza por el cuidado y esmero con que las hicimos", para lo cual utilizaron un "buen barómetro de tubo capilar; en cuyo uso, así como en el cálculo de las observaciones, nos hemos guiado por las reglas y advertencias de los observadores más exactos". Además de los instrumentos referidos, durante su recorrido utilizaron un gnomon de seis pulgadas de alto, fabricado por Felipe Bauzá, para observar las alturas meridianas del Sol y de la Luna, y que resultó mucho más práctico que el sextante y suficientemente exacto para sus necesidades, ofreciendo así indicios no sólo de sus trabajos e instrumentos, sino también de las prácticas científicas vigentes en su época. Entre ellas, determinar "la duración del crepúsculo y calcular la depresión del Sol cuando apuntaba o se confundía con el horizonte la luz crepuscular"?

\footnotetext{
${ }^{6}$ Espinoza y Bauzá, “Observaciones de la velocidad”, pp. 169, 178-180.

7 Espinoza y BauzÁ, “Observaciones de la velocidad”, p. 182.
} 
El resultado de sus quehaceres científicos incluye mediciones, dibujos y descripciones de su travesía andina, los que sirvieron posteriormente para la representación de las cumbres cordilleranas en artísticas aguadas y acuarelas elaboradas por uno de los pintores de la expedición Malaspina, Fernando Brambila. A partir de apuntes y croquis de Bauzá como El Callejón de la Guardia, Perfil de la cordillera de los Andes, La casa última de la cumbre y Elpuente del Inca, el talentoso artista realizó grabados en los que ofreció “vistas de lo más elevado de la cordillera de los Andes”, "de la casa en la cumbre" y del "puente del Inca”, tomas "de estimable valor artístico”, pero también escenas plenamente identificables con las descripciones de los sitios representados textualmente por Espinoza y Bauzá.

De este modo, a fines del siglo XviII, uno de los principales fenómenos geográficos de la ruta más transitada entre Buenos Aires y Santiago, los Andes, quedó científica y artísticamente descrito, medido y delineado. Identificándose ya entonces de manera fehaciente una de las características esenciales de su relieve: "un sinnúmero de ramales"; que los marinos españoles describieron como un paisaje de montañas "sumamente quebradas, estériles y llenas de nieve", compuesto por un “terreno quebrado, árido y espantoso". Ejemplo también de la racional preocupación por las condiciones de tránsito por la cordillera, el comandante de la expedición, Alejandro Malaspina, no dejó de advertir que durante "los cinco meses de esta estación cruel -el invierno- se encierran”. ${ }^{8}$

8 Véase su escrito, "Descripción física del terreno y habitadores de las costas comprendidas entre Chiloé y Coquimbo”, en Sagredo BaEza y González Leiva, La Expedición Malaspina, p. 581. 
Aunque más atentos a las formas exteriores de los Andes, al relieve que se apreciaba a simple vista y a las características del terreno que reconocieron, los científicos ilustrados sin embargo también aludieron a la realidad interna, geológica de "las célebres montañas", que Malaspina describió se "componen de hermoso pórfido"; "tierras cuarzosas y micáceas”, agregó, dimanadas de la descomposición del granito, o de algunas variedades de esquisto y de asperón. "Pináculos del globo" en muchos de cuyos parajes, aseguró, se ven "frecuentes efectos de los terremotos y conmociones que los agitan", de modo tal que, concluyó su caracterización, "de tiempo en tiempo se descomponen muchos de sus cerros, y con sus tierras llenan de tierra las quebradas; mientras otros se desquebrajan y presentan montones horribles de grandes fragmentos de piedras que forman ramplas desde sus vértices hasta el cauce de los ríos”. Elocuente ejemplo del espíritu que animaba a los integrantes de la comisión imperial, la fría descripción que Malaspina hizo de la montaña no impidió que en otro párrafo aludiera a "la cordillera majestuosa de los Andes, cuyas nieves exteriores y ricos metales interiores, asentó de manera aguda, elegante y profética, descubren al mismo tiempo unos grandes objetos de cebo y de escarmiento". 9 Ofreciendo de paso un resumen de la composición geológica de los Andes que en la década de 1830 Charles Darwin estudiaría con detalle.

\footnotetext{
9 En "Descripción física del terreno y habitadores de las costas comprendidas entre Chiloé y Coquimbo", en SAGRedo BAEza y GonzÁlez LeIva, La Expedición Malaspina, p. 580.
} 


\section{UN GEÓLOGO EN LOS ANDES}

Aunque en la cumbre de los Andes Charles Darwin no pudo dejar de conmoverse ante el panorama que apreció, escribiendo "la atmósfera límpida, el cielo azul intenso, los valles profundos, los picos desnudos con sus formas extrañas, las ruinas amontonadas durante tantos siglos, las rocas de brillantes colores que contrastan con la blancura de la nieve, todo lo que me rodea forma un panorama indescriptible”, lo cierto es que su principal interés por la cordillera fue desde su condición de geólogo. ${ }^{10}$

El efecto de los Andes en la experiencia científica de Charles Darwin es de tal trascendencia que se puede sostener que sus Observaciones geológicas en América del Sur es un libro sobre la cordillera, las etapas, formas y consecuencias de su progresiva elevación desde el fondo del océano, y su composición, estructura y características. Todo en un contexto y en un momento en que la geología era una ciencia fundamental en Gran Bretaña y por eso la principal preocupación del joven naturalista. ${ }^{11}$

Además de la elocuencia con que en América la naturaleza ofrece las manifestaciones de la historia geológica del

10 La frase en DARwin, Viaje de un naturalista, p. 302.

11 Así lo refleja el que la primera edición de su viaje se publicara en 1839 como Diario de las investigaciones en geología e historia natural de los distintos países visitados por el Beagle, y que sólo a partir de la segunda edición, en 1845, concluida su obra geológica y cambiado el área de interés de Darwin, el viaje se nombrara Diario de las investigaciones en bistoria natural y geología. Para terminar con el rótulo más conocido de Viaje de un naturalista alrededor del mundo, y en el que la mayor parte de su contenido está dedicado a sus observaciones geológicas en América Meridional y a la cordillera en particular. 
planeta, el impacto que en el joven científico tuvo el ser testigo privilegiado de algunas de las más dramáticas expresiones de la vitalidad de la tierra contribuyó a estimular su interés por la composición interna de los Andes. Por eso en las páginas finales de su relación, cuando resume su viaje, entre las que llama "escenas magníficas" que ha tenido ocasión de contemplar, escribe, están los "volcanes en actividad y los efectos aterradores de un terremoto". Ambos fenómenos, confiesa, "tienen quizá para mí atractivo especial por estar íntimamente ligados a la estructura geológica del globo". ${ }^{12}$

Ya en la costa del Río de la Plata sus hallazgos de restos de animales a kilómetros del océano lo llevaron a pensar en la multiplicidad de las antiguas especies, pero también a reflexionar sobre el levantamiento del terreno de esta "llanura desolada, plana y yerma" que es la pampa. ${ }^{13} \mathrm{La}$ Patagonia lo llevó a exclamar exultante, pero también seguro gracias a la experiencia acumulada como geólogo, "iqué inmensas revoluciones geológicas pueden leerse en esta sencillísima costa!”. ${ }^{14}$

Darwin entró en el Pacífico expectante ante la segura y cercana contemplación de la cordillera. En el extremo sur de América tuvo a la vista los Andes y con ellos su primera impresión ya citada y que culmina con la expresión "un sublime espectáculo".

Más al norte, ya en la zona central de Chile, no pudo dejar de insistir en que era "evidente que toda la línea de la costa ha sido levantada”, lo que, unido a la imponente visión del macizo cordillerano le hizo advertir: "quién podría dejar

12 DARwin, Viaje de un naturalista, p. 449.

13 DARwin, Viaje de un naturalista, p. 106.

14 Darwin, Viaje de un naturalista, p. 162. 
de admirar pensando en la potencia que han levantado estas montañas" ${ }^{15}$ Reafirmando así, aunque ahora con pruebas concretas tomadas de la naturaleza andina, la noción que asociaba la cordillera a lo telúrico, a grandes convulsiones terrestres en tiempos geológicos profundos, resultado de las cuales era la cadena montañosa que Darwin tuvo la oportunidad de explorar en América. ${ }^{16}$

Agudo, una vez que contempló el relieve de Chile escribió que la cordillera era como un inmenso baluarte coronado de trecho en trecho por una torre, un antiguo cráter o un volcán todavía en actividad, sentenciando, "un muro que

${ }^{15}$ Darwin, Viaje de un naturalista, pp. 236 y 240. Antes que Darwin, en 1835, el naturalista de origen alemán, Eduard Poeppig, en la relación de su viaje por América entre 1827 y 1832, escribió a propósito de su acceso a la cumbre de los Andes a la altura del valle del Aconcagua: "Se llega a una región en que todavía parece haberse conservado el caos de los tiempos más remotos. Produce casi espanto pensar en la extraordinaria energía que fue necesaria para dividir tales cerros en dos partes [...]; y cuando la fantasía desarrolla el cuadro de las horrorosas manifestaciones de fuerzas naturales desencadenadas que actuaron aquí en tiempos remotos y que podrían volver a manifestarse en este mismo instante, uno se asusta al enterarse de su propio estado indefenso" (p. 235). Conceptos que Darwin también tendrá cuando, luego de experimentar el terremoto del 20 de febrero de 1835, que tuvo como epicentro Concepción, escribió: "un temblor de tierra subvierte en un momento las ideas más arraigadas; la tierra, el emblema mismo de la solidez, ha temblado bajo nuestros pies como una cáscara delgada; el espacio de un segundo ha bastado para despejar en el espíritu un extraño sentimiento de inseguridad" (p. 283). ${ }_{16}$ Mientras Darwin recorría la cordillera entre 1834 y 1835, el artista viajero, Juan Mauricio Rugendas, residente en Chile entre 1834 y 1842, representaba los Andes en numerosos cuadros, transformándolos en protagonistas de su producción pictórica en Chile. Conjunto que ha sido interpretado como "paisajes telúricos", y en los que "pintó al óleo un espectáculo de fin de mundo". Véase Diener, La obra de Juan Mauricio Rugendas, pp. 18-21. 
limita de un modo perfecto al país". ${ }^{17}$ En Chiloé, el volcán Osorno, el Corcovado y otros que no individualiza, lo llenan de admiración, pero también de ideas sobre el origen volcánico "de los conos inmensos cubiertos de nieve que se levantan hacia el Sur". Una cadena que, informa, extendiendo en profundidad el tiempo geológico, está "compuesta de grandes masas de granito, sólidas y abruptas que parecen contemporáneas de los principios del mundo". ${ }^{18}$

Fue el interés geológico lo que llevó a Darwin a internarse en la cordillera, cruzándola en ambos sentidos y por diversas rutas en marzo y abril de 1835. El viaje hasta Mendoza lo hizo por el paso de Portillo, más elevado y peligroso que el del Aconcagua, por el cual regresó hacia Chile, y que fue el utilizado por los oficiales españoles José Espinoza y Felipe Bauzá en 1794.

En la relación de su viaje hacia Mendoza fue describiendo el relieve que atravesó desde su salida de Santiago y que a través del valle del Maipo penetra en la cordillera, oportunidad en la que explica sus características, "formado por terrazas de guijarros y arena dispuestas en capas groseramente estratificadas", y las condiciones de su formación, "terrazas acumuladas durante la elevación gradual de la cordillera". Deduciendo entonces que la que llama "gran cordillera, en lugar de haber surgido de repente, como creían antes todos los geólogos, y todavía hoy muchos, se ha levantado lenta y gradualmente, del mismo modo que las costas del Atlántico y del Pacífico en un periodo muy reciente". ${ }^{19}$

17 DARwin, Viaje de un naturalista, p. 240.

18 DARwin, Viaje de un naturalista, p. 264.

19 DARwin, Viaje de un naturalista, p. 295. 


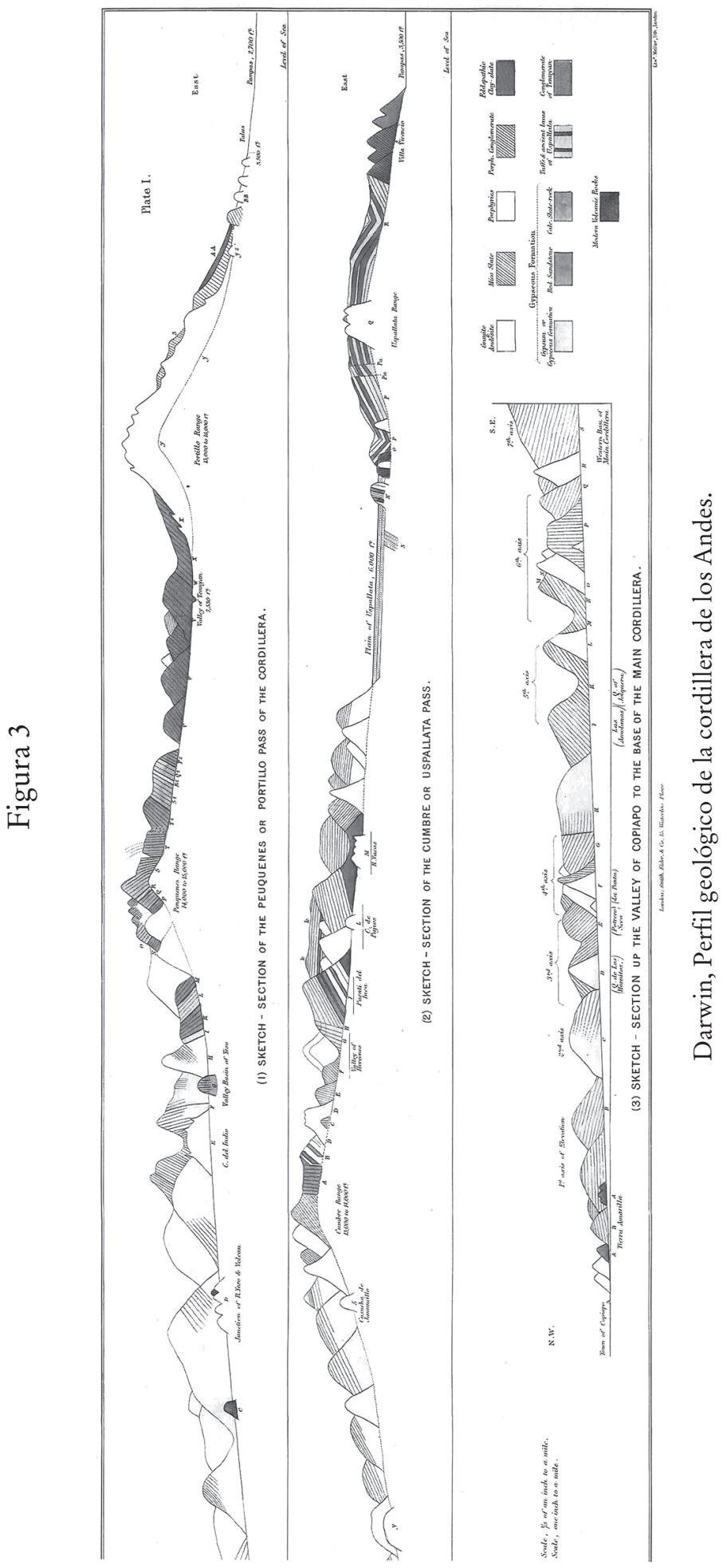


Interesado sobre todo en la que llama "estructura de la cordillera", provisto de su libreta de apuntes, de Principles of Geology de Charles Lyell, de su martillo y de su cincel para tomar muestras, y de sus instrumentos de medición, Darwin registró la estratificación y su naturaleza en los Andes, recogió todo tipo de especies y fósiles, y recopiló información fáctica sobre la altura de las montañas y su composición geológica, utilizando un vocabulario técnico: "roca rojiza", "aluvión estratificado", "fallas llanas", "terrazas", "rocas de pórfido", "diques continuos”, "pilas cónicas de detritus" y "puntas centrales", entre otros términos, que le permitieron comenzar a definir la orografía e identificar los "macizos montañosos del exterior de la cadena" y en definitiva concluir sobre la existencia "de las diferentes cadenas que forman la Cordillera". ${ }^{20}$

Independiente de la precisión absoluta, Darwin identifica las formas orográficas que décadas después serán antecedentes indispensables de conocer y referir en las controversias territoriales nacionales por la soberanía de los Andes. En su diario de viaje escribió sobre la cadena que nombra de Peuquenes, con alturas máximas de casi $4000 \mathrm{~m}$, y la de Portillo, más al este, con $4292 \mathrm{~m}$, agregando que mientras la cadena del oeste está formada de pórfidos, gres rojo, conglomerado y esquisto arcilloso, la de Portillo ofrece una conformación enteramente diferente, lo principal, asegura, granito rojo y gres transformado en cuarzo, todo lo cual le permite deducir, a partir de la composición y ubicación de las rocas, que Portillo, "la cadena más elevada de esta parte de la cordillera, no es tan antigua como Peuquenes, menos

${ }^{20}$ DARwin, Viaje de un naturalista, pp. 296-299. 
elevado", concluyendo "que la mayor parte, si no en toda la cordillera, cada cadena se ha formado por levantamientos e inyecciones reiteradas, y que las diferentes cadenas paralelas tienen edades distintas". ${ }^{21}$

Agudo observador, prolijo científico, el naturalista en medio de los Andes mide, observa y describe los fenómenos que se le ofrecen: la extrema transparencia del aire, la sequedad de la atmósfera, las condiciones de la circulación de los vientos, la alteración de la presión atmosférica, las nieves perpetuas, las temperaturas extremas, la oscilación del tiempo atmosférico, la escasa vegetación y fauna, el resplandor de la luna y de las estrellas, incluso "la extraordinaria facilidad con que la electricidad se desarrolla en estos parajes". ${ }^{22}$ Aludiendo también a los efectos de la puna, es decir, a la dificultad para respirar por causa de la altura, con humor, escribió, revelando reconocidas evidencias de sus teorías, "en cuanto a mí, repito, me ha bastado la vista de algunas conchas fósiles para curarme en el acto". ${ }^{23}$

Todo al servicio de la descripción de un fenómeno natural, la cordillera de los Andes, que según la perspectiva que adopte será "una barrera infranqueable", si alude a la distribución de las especies animales y vegetales a uno y otro lado de sus faldas; "muro gigantesco", en relación con los vientos y la circulación general de la atmósfera; "frontera”, en función de la capacidad de defensa de Chile; paisaje "grandioso y severo", cuando observa las faldas redondeadas y desnudas en medio de la montaña; "aluvión estratificado,

21 DARWIn, Viaje de un naturalista, p. 299.

22 DARWIn, Viaje de un naturalista, pp. 300-304.

23 DARwin, Viaje de un naturalista, p. 300. 
terrazas, colores brillantes, rocas de pórfido enteramente peladas, diques continuos, capas, puntas centrales abruptas, pilas cónicas", cuando alude a la composición de los macizos montañosos del exterior de la cadena. ${ }^{24}$

El regreso a Chile por Uspallata, iniciado en Mendoza el 29 de marzo de 1835, sirvió a Darwin para reconocer y evaluar la ruta y en especial para confirmar sus apreciaciones sobre las características y composición geológica del macizo andino. A lo largo del camino también observó montañas paralelas, deteniéndose en la que llama "parte central de la cadena”, que midió y describió, diferenciándola de la de Portillo, entre otros antecedentes gracias a los árboles petrificados convertidos en sílice que identificó a una altura de $2100 \mathrm{~m}$. Todos hechos que le permitieron deducir su origen, señalar su composición, edad geológica y, sobre todo, ponderar la elocuencia de la naturaleza, transformándola de paso en artilugio científico cuando, atravesando Uspallata, al disfrutar de una "vista extraordinaria", escribió: "rocas de sedimento rojas, purpúreas, verdes y otras completamente blancas, alternando con lavas negras, rotas y arrojadas con el mayor desorden entre masas de pórfido"; y concluyó, "es la primera vez que se presenta un espectáculo que me recuerda esos preciosos cortes que hacen los geólogos cuando quieren representar el interior de la tierra". ${ }^{25}$

A continuación de lo cual volvió a la naturaleza, a su tránsito por la "cadena central", y a la subida en zig-zag hasta la cumbre, culmen que entonces transforma en sinónimo de "línea divisoria de las aguas"; la cresta de la montaña, asienta

24 Darwin, Viaje de un naturalista, pp. 293-298.

25 Darwin, Viaje de un naturalista, p. 310. 
en su relato, donde, ahora relativizando y multiplicando las formas que aprecia, describe: la "vista es admirable: al Oeste se domina un magnífico caos de montañas separadas por desfiladeros profundos". ${ }^{26}$

Expresión del interés y de los trabajos emprendidos por Darwin sobre la composición geológica de los Andes son las "Notas geológicas tomadas durante un reconocimiento de las costas oriental y occidental de América del Sur en los años 1832, 1833, 1834 y 1835, con la relación de un corte transversal de la Cordillera de los Andes, entre Valparaíso y Mendoza" que, remitidas por correo, fueron presentadas en la Geological Society por su mentor, el geólogo Adam Sedgwick, en noviembre de 1835. Hecho que refleja la urgencia por dar a conocer las novedades científicas, las formas de circulación del conocimiento, la relación entre el campo de experimentación y los centros académicos; en definitiva, las formas y las prácticas de los hombres de ciencia.

En su producción científica sobre la geología americana y andina, Darwin no sólo exhibió las huellas que la evolución del relieve en América dejó en su quehacer como científico, sino también el impacto que la contemplación y estudio de la cordillera de los Andes tuvieron en su producción. Entre 1842 y 1846 dio forma final a su trabajo como geólogo con la publicación de libros dedicados a esta ciencia. Se trata de La estructura y distribución de los arrecifes de coral (1842); Observaciones geológicas de las islas volcánicas visitadas durante el viaje de HMS Beagle (1844), y Observaciones geológicas en América del Sur (1846).

${ }^{26}$ Darwin, Viaje de un naturalista, p. 313. 
En todos ellos, como en su obra posterior, se repite un esquema que implica ofrecer la descripción de evidencia, que en el caso del libro sobre América incluye la composición, datación, historia geológica y edades, características de las formaciones, y las especies asociadas a las edades de la Tierra, buscando explicar las causas de los fenómenos que lo ocupan. Todo siempre acompañado de una concepción en virtud de la cual los fenómenos son fruto de procesos progresivos, efecto de la acumulación, en donde pequeños detalles pueden explicar la majestuosidad de la naturaleza.

En Observaciones geológicas en América del Sur, en el capítulo VII, que tituló "Chile Central-Estructura de la Cordillera”, expuso con prolijidad las formas y composición de los Andes, que llamó "cordillera principal”. Una formación de "rocas visiblemente estratificadas", con estratos inclinados en ángulos que varían entre los 10 y los 20 grados, aunque también encontró de 40 grados; con estribaciones exteriores y cordones centrales más elevados donde, describió, los estratos se presentan muy inclinados o verticales.

No escapó a la observación de Darwin que en la cordillera de los Andes los estratos de las diversas rocas se presentaban mucho más deformados que aquellos frecuentemente horizontales, más modernos, existentes en muchas de las regiones costeras del continente americano. Por eso, dibujó estas estructuras de deformación en los tres perfiles geológicos que realizó durante sus travesías por los Andes. Por medio de estas representaciones, tal vez las primeras de la estructura geológica del cordón montañoso que recorre América del Sur, mostró las diversas inclinaciones de los estratos de roca, los pliegues que describen y las fallas geológicas que los cortan, en versión bastante similar a las modernas. 
Lo que le permitió concluir: "la cordillera en todo Chile se compone de varias líneas de montañas paralelas anticlinales y monoclinales, que corren al norte, o al norte con inclinación al oeste y al sur". Agregando todavía que "algunos cordones exteriores y mucho más bajos se desvían a menudo considerablemente de este curso, y se proyectan como contrafuertes oblicuos desde las cadenas principales". ${ }^{27}$

Una conclusión que refleja que, como forma de relieve y objeto de estudio geológico, la cordillera de los Andes fue para Darwin un fenómeno natural flexible y multiforme cuya heterogénea composición interna identificó y describió. Características que en lo relativo a su orografía fue perdiendo a lo largo del siglo XIX y a medida que los naturalistas al servicio de los estados nacionales la reconocieron y caracterizaron, pues estos la representaron como una barrera que separaba a Chile de Argentina. Un espacio geográfico ahora sólo relevante porque contenía el límite ente ambas Repúblicas, la línea de las más altas cumbres que dividen las aguas, un fenómeno natural que buscaron con afán dejando como testimonio de sus intereses numerosas descripciones de diferentes cumbres de los Andes, todas parciales y localizadas, pero que sin embargo fueron aprovechadas para obtener una visión general de la cadena montañosa. Mostrando así la polifonía de miradas, experiencias y representaciones que el macizo cordillerano estimuló, entre ellas, las que resultaban de su apreciación como forma distintiva de la Tierra, o las que se derivaban de su condición de fenómeno geográfico particular de América Meridional.

27 Darwin, Observaciones geológicas, p. 280. 
LOS ANDES EN LA CARTOGRAFÍA NACIONAL

El científico que prácticamente dedicó su vida a explorar y dar a conocer Chile, labor por la cual fue reconocido con la Legión de Honor y su admisión en la Academia de Ciencias de París, fue el primero en representar "científicamente" el territorio chileno y, por lo tanto, la cordillera de los Andes en una extensión que cubre entre los $26^{\circ}$ y $44^{\circ}$ de latitud sur y los $71^{\circ}$ y $74^{\circ}$ de longitud oeste. Así puede apreciarse en la representación del naturalista, fechada en 1841 como "Mapa de Chile levantado por orden del gobierno de esta república por Claudio Gay", verdadero anticipo del publicado en su Atlas en 1854 como "Mapa para la inteligencia de la Historia física y política de Chile".

La cartografía de Gay ilustra literalmente lo advertido por el botánico de origen alemán, Eduard Poeppig, que permaneció en Chile entre 1826 y 1829 explorando el territorio, y quien en la relación de su viaje asentó, aludiendo a la cordillera, que se trataba de una "naturaleza gigantesca", con "una rígida majestad" que, en lo que llama Andes superiores, ofrece un "carácter inmensamente soberbio y severo"; los que "mirados de cerca o de lejos se presentan siempre como una muralla continua, que se extiende en fila ininterrumpida a lo largo de sesenta grados de latitud", concluyendo su alusión a la forma que también llamó "vértebra del mundo". 28

Entre los estímulos que el gobierno tuvo para contratar al naturalista francés en 1830, fue determinante el relacionado con la posibilidad de contar con una cartografía fiable,

${ }^{28}$ Poeppig, Un testigo en la alborada de Chile, pp. 240, 242, 248, 249 y 251. 
entonces inexistente. La preparación de un mapa de Chile, que Gay se comprometió a publicar "en grande escala”, fue una de las tareas que inició desde el momento mismo de su llegada, en 1828. Muestra de su interés por estudiar y representar las que llama "comarcas tan poco visitadas por los naturalistas”, en diciembre de 1829 escribió al geólogo Alexandre Brongniart, informándole que en Chile se había "ocupado también de medir la altura de varias montañas, no con el barómetro sino por operaciones trigonométricas", ${ }^{29}$ identificando así sus métodos de trabajo.

Lo que para el científico resultaba una práctica inherente a su quehacer, para el gobierno de la época era una tarea digna de destacarse, como para mencionarla en la memoria que el ministro del Interior presentó al Congreso Nacional en 1836, en la que asentó que entre los resultados que el "viaje científico" había podido dar hasta ese momento, "no es el menos interesante la formación de un mapa de las provincias recorridas por el ilustre viajero". ${ }^{30}$ Además señalaba de paso lo que para el Estado resultaba esencial entonces, contar con un mapa político del territorio bajo su soberanía, en el que el orden político administrativo en que estaba organizada la República estuviera representado. Necesidad apremiante que en mayo de 1842 volvió a ser recordada cuando el ministro de Culto e Instrucción Pública escribió que uno de los primeros trabajos de Gay una vez de regreso en Francia sería "la publicación en grande escala del Mapa geográfico de Chile, y de un atlas de cada una de las provincias; obra

${ }^{29}$ Feliú Cruz y Stuardo Ortiz, Correspondencia de Claudio Gay, fechada el 9 de diciembre de 1829, pp. 2-3.

30 Stuardo Ortiz, Vida de Claudio Gay, I, pp. 412-413. 
Figura 4

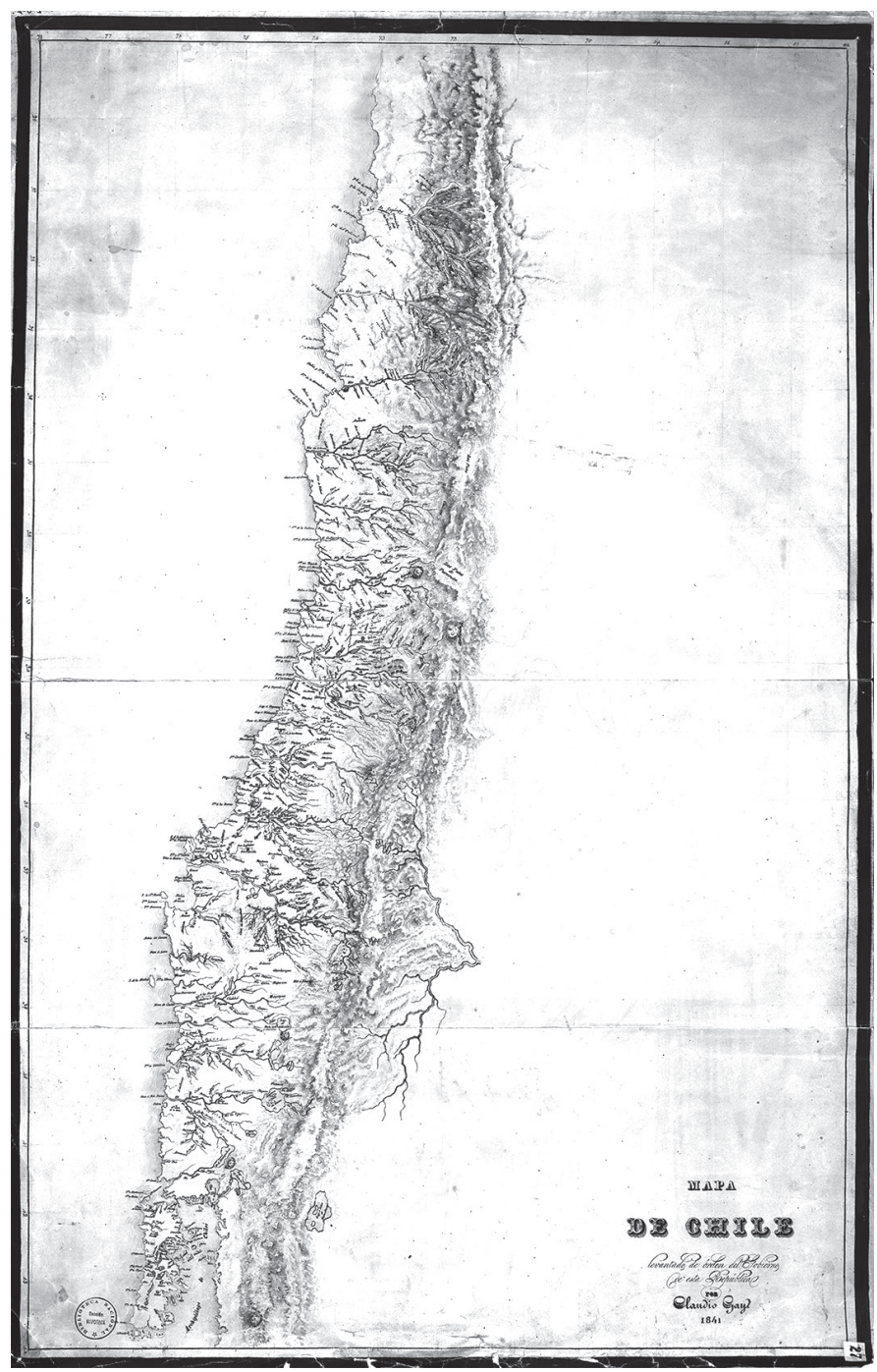

Mapa de Chile de Claudio Gay. 1841. Biblioteca Nacional de Chile. 
que justamente considera el Presidente de la República de urgente importancia, atendida la falta que se experimenta en el país de un mapa exacto y adecuado a las exigencias del servicio público". ${ }^{31}$ Palabras y conceptos que reflejan las necesidades que la ciencia estaba satisfaciendo por medio de sus investigaciones.

Tal vez por la naturaleza de la representación que se requería, esencialmente política, en la primera cartografía de Gay la cordillera de los Andes prácticamente no aparece como relieve, aunque sí como topónimo de un fenómeno natural existente. Así se puede advertir en el borrador de su mapa de Chile, esbozado a mediados de la década de 1830, y también en la versión definitiva publicada en 1854 en París y como parte de su Atlas de la historia física y política de Chile, en el cual también se incluyen los mapas de cada una de las provincias. Sin embargo, la presencia del macizo no podía ser obviado por el científico y en un mapa intermedio entre ambos, el datado por el naturalista en 1841, la cordillera se representa con toda claridad a lo largo del flanco derecho del considerado entonces territorio de Chile, ocupando, según la latitud que se observe, más o menos superficie desde el este hacia el oeste.

Utilizando la técnica del achurado como elemento diferenciador del relieve, Gay ofrece entonces por primera vez una versión gráfica extendida de este fenómeno natural, representando su presencia a lo largo de todo el territorio nacional, incluidas las estribaciones y cordones paralelos que lo conforman, y como una forma geográfica imposible de soslayar que en este mapa, además, se ofrece asociada a

31 Stuardo Ortiz, Vida de Claudio Gay, I, pp. 439-440. 
otras referencias naturales, como ríos, cerros, islas, lagos y formas del litoral, como puntas, bocas, bahías y el archipiélago de Chiloé, todo acompañado de una toponimia esencial, indicando, como asegura Gay, "la posición relativa de los parajes". 32

Obligado por sus trabajos de geografía a realizar frecuentes excursiones al origen de los ríos - "atravesé las cordilleras por más de cuarenta partes diversas" aseguró en 1841-, el naturalista apreció durante sus exploraciones andinas lo que llamó "un laberinto de montañas" en los informes de sus estudios de las provincias, ocasiones en las que a veces también alcanzó hasta "el centro de la cordillera", examinando el camino "que conduce a la otra banda". ${ }^{33}$ Aunque la representación andina no refleja exactamente el relieve que Gay apreció, ella resulta suficiente para identificar de manera gráfica el que su experiencia fue configurando como el margen oriental del territorio del Estado nacional para el cual exploraba. Noción que fue desarrollando a medida que recorrió el país, y que ya en 1835, y a propósito de un ensayo sobre la geografía física de la provincia de Valdivia, concluyó era límite natural de Chile hacia el este. Andes que describió, ahora más precisamente, como "montes que se nos presentan en una confusión que parece no dar cabida a nuestras clasificaciones y métodos", asentando de modo concluyente que la cordillera no era una formación uniforme, sino compuesta por "cadenas", "picos elevadísimos" y "ramales que se extienden en sentido longitudinal". ${ }^{34}$ Habían sido los

\footnotetext{
32 Stuardo Ortiz, Vida de Clandio Gay, II, p. 218.

${ }^{33}$ Stuardo Ortiz, Vida de Claudio Gay, II, pp. 74, 96, 159 y 215.

34 Stuardo Ortiz, Vida de Claudio Gay, II, pp. 194-195.
} 
que Gay califica de "largos viajes a la base de la cordillera”, los que le habían permitido apreciar y reconocer las múltiples formas que ofrecía el macizo, entre ellos los conos volcánicos que representa en su mapa de $1841 .^{35}$

Provisto de los instrumentos para sus observaciones que había adquirido en Europa, los más modernos existentes en la época, como agujas para medir la declinación magnética, imanes, agujas para levantar planos, aparatos para calcular la latitud, cronómetros, microscopios, telescopios, barómetros, termómetros, higrómetros, eudiómetros, areómetros, un artefacto para observar la electricidad atmosférica y hasta una cámara oscura; y consciente del valor de sus representaciones, Gay más de una vez explicó que durante sus excursiones se propuso averiguar la posición relativa de los parajes que le eran conocidos o que le nombraban sus guías, determinar la posición de los puntos más señalados, establecer los límites de las provincias, y dar a conocer el origen, dirección y extensión de los ríos, entre otros objetivos básicos para delinear sus mapas. Una tarea que definió como un "trabajo de gran utilidad" para las operaciones administrativas del gobierno. ${ }^{36}$ Confirmando de este modo el carácter estatal, nacional, de sus trabajos, y, desde entonces, de la mayor parte del conocimiento científico que se produjo en el país para la ilustración y orientación local.

Consciente de la necesidad de señalar sus métodos, en 1836 escribió al ingeniero geógrafo Edme François Jomard, miembro del Instituto de Francia, dándole noticia de los

\footnotetext{
35 Stuardo Ortiz, Vida de Claudio Gay, II, p. 197.

36 Véanse los informes sobre sus viajes a las provincias de Valdivia y Chiloé de julio de 1836 y de Coquimbo de febrero de 1831. En STUARdo Ortiz, Vida de Claudio Gay, II, pp. 211 y 218.
} 
trabajos que había realizado, exponiendo entonces que siempre exploró provisto de un círculo de reflexión, de un anteojo astronómico de Robert Cauchoix y de tres buenos cronómetros, todos instrumentos que le habían permitido "determinar la latitud y longitud de los principales puntos que he coordinado después por triangulaciones magnéticas". El resultado, un mapa que, aseguró, "difiere de todos los que se han publicado hasta el presente". ${ }^{37}$

La importancia del "Mapa de Chile levantado de orden del gobierno de esta república por Claudio Gay, 1841" se puede apreciar desde numerosas perspectivas. ${ }^{38}$ Por un lado, su valor en tanto representación geográfica del territorio chileno en una época en que las mismas son prácticamente inexistentes, algunas muy poco confiables o inaccesibles para los chilenos, pero también por señalar no sólo los principales accidentes del relieve, sino sobre todo por identificar los Andes como elemento delimitador del territorio nacional. Un país, como Claudio Gay escribió en 1854, "perfectamente limitado por barreras infranqueables: al norte por el vasto desierto de Atacama, al sur y al oeste por el océano Pacífico, y al este por esas grandes cordilleras que lo recorren en toda su longitud". ${ }^{39}$

El mapa ofrece la visión existente en el Chile del siglo XIX sobre los espacios que conformaban su territorialidad.

37 Feliú Cruz y Stuardo Ortiz, Correspondencia de Claudio Gay, p. 16.

38 De 100 por 63 centímetros aproximadamente, el mapa fue recientemente encontrado entre la cartografía que se conserva en la sección mapoteca de la Biblioteca Nacional de Chile.

39 Feliú Cruz y Stuardo Ortiz, Correspondencia de Claudio Gay, pp. 318-319. 
Es la materialización cartográfica de una realidad natural. Es decir, un Chile ajeno, como lo era en realidad, a los inhóspitos desiertos de sus extremos y totalmente circunscrito al breve espacio que la cordillera de los Andes deja antes de alcanzar el mar; todavía sin expresar, como lo haría en el mapa geográfico de 1854, la aspiración de ejercer soberanía efectiva en la Patagonia occidental hasta el estrecho de Magallanes. Un territorio de gran desarrollo latitudinal que, reflejando las pretensiones nacionales, contrasta con la percepción colonial del espacio en función de ejes este-oeste, cordillera-mar, organizados en función de valles y ríos, como por ejemplo el mapa de Espinoza y Bauzá lo refleja al representar los intereses imperiales. ${ }^{40}$

Con su acción, y aplicando el conocimiento que le dieron sus viajes por el país, Claudio Gay siguió el modelo geográfico entonces imperante. El señalado por Alexander von Humboldt al identificar y caracterizar los espacios naturales a partir de los elementos que los distinguían que, en este caso, resultó en la delimitación de Chile, tanto en su condición de unidad natural como política. No por nada escribió que, si el globo se dividía en regiones en razón de la apreciación de los géneros y especies peculiares a cada una de ellas, "ningún país más digno de ser elevado al título de región que la república de Chile. Perfectamente limitado por barreras infranqueables". ${ }^{41}$

${ }^{40}$ El eje vertical norte-sur que terminará estructurando Chile, que Gay anticipa en su obra científica, tendrá en el ferrocarril longitudinal construido a lo largo del siglo XIX una expresión material elocuente. Véase Sagredo Baeza, "El Atlas de Gay y la obsesión por representar Chile", p. 46.

41 "Fragmentos de geografía botánica de Chile", presumiblemente de 
El mérito de Claudio Gay fue fundar la geografía chilena, en el sentido de definir el espacio nacional y diferenciarlo de otros por sus fronteras, entre ellas las cordilleranas, sustrayéndolo así de la visión geográfica continental, regional, amplia, que, al modo de Humboldt, había caracterizado el estudio de los naturalistas hasta comienzos del siglo xIX.

Claudio Gay pudo dar a conocer la configuración, la fisonomía topográfica del país y delinear cartográficamente Chile, pues lo había estudiado exhaustivamente, identificado como una realidad geográfica y caracterizado en sus rasgos más sobresalientes desde el punto de vista ambiental. Así se puede apreciar en la sección destinada a la historia natural de su Historia física y política, donde abordó el estudio de la flora y fauna del país bajo los rótulos de botánica y zoología, sosteniendo que Chile sobresalía porque tenía un carácter particular derivado de las barreras naturales que cerraban todo su contorno, transformándolo en una "región enteramente natural"; que sin embargo las pretensiones territoriales fueron modificando a lo largo del siglo xIx, incluso contra la evidencia geográfica que, como sabemos, puede ser alterada por las pretensiones políticas.

Hasta la aparición de la Geografía física de la república de Chile de Amado Pissis en 1875, que incluyó un atlas del país levantado luego de una completa medición geodésica del territorio comprendido entre Copiapó y el río Biobío, la cartografía de Chile de Claudio Gay fue la usada por el Estado y sus agentes, así como por los particulares, a pesar de las omisiones y errores que contenía. Carencias que, sin embargo, no influyeron en el papel atribuido y en

1854, en Stuardo Ortiz, Vida de Claudio Gay, II, pp. 318-329. 
la magnitud de la presencia de los Andes en el territorio chileno, el que, teniendo la obra de Gay como referencia, fue explorado por agentes tanto estatales como institucionales, nacionales y extranjeros, a lo largo de todo el siglo XIX, ahora para identificar sus características y formas específicas. Información que no sólo sirvió como antecedente para invertir por parte de los capitales europeos, sino que también, y tal vez sobre todo, fue utilizada para el ejercicio de la soberanía por parte del Estado. Como también lo demuestra el esfuerzo realizado en Argentina por reconocer científicamente su territorialidad, empresa en que los Andes también fueron protagonistas.

\section{NATURALISTAS EN LOS ANDES}

Una vez representada como referencia nacional en el mapa físico de Claudio Gay de 1841, la cordillera de los Andes continuó siendo estudiada por otros científicos que la exploraron detenidamente y por las más diversas razones, comúnmente asociadas a las riquezas minerales que contiene, para extender el conocimiento sobre secciones de ella o para cartografiarla con exactitud. Entonces se inició una etapa durante la cual se pasó de la preocupación por la estructura orográfica y geológica general de los Andes, a la exploración, descripción, medición y situación de cerros, volcanes, cajones y valles cordilleranos. Todos estudios parciales, pero cuyos resultados sirvieron para la preparación de obras generales sobre la geografía de Chile, América del Sur y el cosmos, como llamó Humboldt a su obra cumbre. Cada una de las cuales ofreció una representación de los Andes que alternativamente la apreciaba como forma de la 
naturaleza local o global, multiforme o uniforme, muestra a su vez de la flexibilidad de la realidad natural en tanto objeto de estudio científico.

Entre los exploradores más sistemáticos de los Andes estuvo el profesor de química y mineralogía de origen polaco Ignacio Domeyko, llegado a Chile en 1838 para desempeñarse como docente en La Serena, quien desde su arribo comenzó a recorrer la cordillera en las provincias de Atacama y Coquimbo, entonces las más septentrionales de Chile. Excursiones mineralógicas que a lo largo de los años y sucesivamente lo llevaron a reconocer el macizo, haciendo observaciones particularmente agudas y de gran proyección sobre sus características. Sus textos se transformaron en referencias obligadas sobre la historia natural americana.

Pero había sido en su travesía desde el Río de la Plata hacia el Pacífico, en medio de la pampa, el 10 de mayo de 1838, mirando al poniente, en lo que consideró "un instante importante en nuestro viaje", que Domeyko tuvo "la primera vista de la Cordillera, ese lomo o espina dorsal de las dos Américas, la cadena montañosa más grande del mundo", y con ella una caracterización general del "inmenso macizo" que con los años complementó con descripciones minuciosas. $^{42}$

En la crónica de su excursión a las cordilleras de Copiapó a mediados de 1843, Domeyko, que para entonces ya había explorado otras porciones del macizo en el centro del territorio de Chile para, como escribió, "estudiar la formación de los cerros y familiarizarme con la geología del país”, ofrece algunas conclusiones de las observaciones y estudios que

${ }^{42}$ Domeyko, Mis viajes, I, pp. 326-327. 
lo habían llevado a internarse y elevarse "hasta los puntos más remotos y eminentes del sistema de aquellas inmensas serranías". ${ }^{43}$

Recorriendo las que llama "cumbres de los majestuosos Andes”, observó algunos fenómenos geográficos que su recorrido por Copiapó le permitió confirmar y asentar como constantes en los Andes chilenos. Entre ellos, valles cordilleranos que a medida que se avanza hacia el este se van estrechando hasta desaparecer; la existencia de dos o más ríos afluentes y origen de uno principal que será el que bajará serpenteando el valle, para él un "punto muy importante en la geografía del país”; las múltiples direcciones de los ríos cordilleranos, este-oeste, sur-sureste, norte, este, noroeste; y la "confusión en rocas, cerros y terrenos, señales de las revoluciones del globo". ${ }^{44}$ Confirmando de este modo la diversidad de la naturaleza y formas andinas que otros antes que él ya habían advertido. De hecho, en un escrito muy posterior, que data de 1875 , un estudio del relieve y la configuración del territorio chileno presentado al Congreso Internacional de Ciencias Geográficas de París, el entonces rector de la Universidad de Chile aborda detalladamente la configuración de los Andes y fenómenos asociados a ellos por medio de conceptos como: "sistema de cordilleras", "numerosos ramales", "eslabones occidentales", "línea central del solevantamiento", "lomo de los Andes", "ramales", "un ramal de cordillera" y "línea central de los Andes", entre otros, los cuales dan cuenta de la

${ }^{43}$ Domeyкo, Excursión a las cordilleras de Copiapó, p. 3.

${ }^{44}$ Domeyкo, Excursión a las cordilleras de Copiapó, pp. 20 y 23. 
variedad de formas que había reconocido en la cordillera. ${ }^{45}$ Muestra a su vez que en sus excursiones, además de los instrumentos básicos, sus principales herramientas fueron sus conocimientos de geología, su capacidad para analizar e interpretar las formas orográficas, los conceptos, principios, técnicas y métodos adquiridos mediante el estudio y la práctica en terreno. Reflejo de lo cual es su manual de Mineralojía. Que comprende principalmente las especies mineralójicas de Chile, Bolivia, Perú y Provincias Arjentinas, cuya primera edición data de 1854 y que mereció otras dos en 1860 y 1879, y en el cual los Andes constituyen el escenario esencial para desplegar sus conocimientos sobre el ramo de la historia natural que se ocupa del Reino Mineral.

Ejemplo de la aplicación tanto de su saber como de su interés por dar a conocer el territorio que exploró, en las memorias de sus viajes por el país Domeyko utilizó diversos términos para describir los Andes, como "estribaciones de las montañas", "ramificaciones y derivaciones de las montañas", "pendientes abruptas" y "portezuelo", con descripciones que contradecían nociones arraigadas.

De su ascenso al volcán Antuco en 1845, que entre otras tuvo como "intención averiguar aquí la verdadera frontera de Chile y llegar al otro lado de los Andes", escribió, "en el lugar llamado La Cueva se unen dos arroyos; uno viene del sur, de Sierra Velluda, y el otro desciende desde la línea divisoria de aguas en las crestas de los Andes, los que, según

\footnotetext{
45 Véase Jeografía jeológica. Estudio del relieve o configuración exterior del territorio chileno con relación a la naturaleza jeológica de los terrenos que entran en su composición, en Estudios jeográficos sobre Chile. Memorias relativas a varias cuestiones sometidas al Congreso Internacional de Ciencias Jeográficas de París de 1875.
} 
veo, están bastante lejos al este de Antuco”. Una constatación importante, que buscaba atender una de las preocupaciones políticas de la época, como lo refleja el párrafo con que Domeyko continúa su relación, ahora conclusión: "Esta cresta y la línea de división de las aguas, es decir, la frontera oriental de la República chilena con la vecina de Argentina, no pasan, como se cree comúnmente, por las más elevadas cumbres andinas como Antuco, Sierra Velluda o Chillán, sino que están situadas bastante lejos de éstas, hacia el este". ${ }^{46}$

Su conocimiento de la cordillera permitió a Domeyko distinguir la configuración del macizo según tramos. Desde Atacama hasta el Aconcagua, escribió en 1849, luego de un viaje a las cordilleras de Talca y de Chillán, en general conservan los Andes el mismo carácter, poca variedad en sus formas y pocas cumbres aisladas; pero acercándose a los $33^{\circ}$, adquieren un aspecto algo diferente y mayor anchura, afirmó, al tiempo que también se manifiesta en sus relieves “cierta complicación”, así como nuevas rocas y formaciones aparecen en su superficie. Ahí se inicia una nueva sección de la cordillera, que ejemplifica con el Tupungato, y sobre la cual afirma, "hasta ahora no se ha determinado con exactitud su base, su altitud y su situación con respecto a la línea divisoria”. Lo califica un lugar de transición, avizorando, como efectivamente se confirmaría con los años, que ese era un sitio que presagiaba "nuevas formas y variaciones para las cordilleras del sur”. ${ }^{47}$ Según Domeyko el

46 Domeyno, Mis viajes, pp. 757-758.

47 En febrero de 1861, Domeyko realizó la que llamó una excursión geológica a las cordilleras de San Fernando, que le permitió conocer la que consideraba una de las secciones de los Andes "hasta ahora menos 
último eslabón de este trecho parecía hallarse frente a San Fernando, en la cumbre del volcán Tinguiririca; a partir de ahí, "el cordón de los Andes comienza a bajar visiblemente, se angosta y se simplifican sus ondulaciones". ${ }^{48}$ Atento a la "línea que termina las lomas y las crestas de esta cadena", a las "masas sobresalientes" y a los "puntos prominentes", es decir, a los fenómenos que delimitan, concluye, luego de explorar la cordillera a la altura de Chillán, que por la cima del Descabezado, Planchón, Cerro Azul y Cerro Nevado de Chillán, "pasa la línea de la región más elevada de los Andes, pero no la línea divisoria de las aguas, la cual corre al otro lado de aquélla, a una tres o cuatro leguas (14 a $19 \mathrm{~km}$ ) más al oriente". ${ }^{49}$

El interés por conocer el territorio, del cual la cordillera es una parte esencial, explica los numerosos escritos sobre diferentes aspectos del macizo andino aparecidos en los Anales de la Universidad de Chile, la principal publicación científica del país y cuyo primer número apareció en 1846. Descripciones de exploraciones, mediciones y relatos de viajes, características de su composición geológica, de las condiciones del clima en diferentes tramos y cumbres, precipitaciones, glaciares y otros diversos aspectos de la historia natural de los Andes fueron dando forma y contenido a la cadena montañosa a lo largo del siglo gracias a trabajos como el de Ignacio Domeyko, publicado en 1850, y cuyo título resume bien el carácter de los textos que fundan

visitadas y menos conocidas por los viajeros". Entonces también se interesó por la "línea central de los Andes" (Anales de la Universidad de Chile, 1862, pp. 23-33).

48 Domeyкo, "Viaje a las cordilleras de Talca i de Chillán”, pp. 7-8.

49 Dомечко, "Viaje a las cordilleras de Talca i de Chillán”, p. 18. 
nuestra interpretación: "Esploración de las lagunas de Llanquihue i de Pichilaguna. Volcanes de Osorno i de Calbuco. Cordillera de Nauelhuapi". ${ }^{50}$

Incluso para observadores menos preocupados por las formas y estructuras de la cordillera de los Andes, como el teniente James M. Gilliss que encabezó una expedición astronómica naval de Estados Unidos al hemisferio sur entre 1849 y 1852, los Andes resultaron una realidad esencial y multiforme. No sólo porque marcaba el límite oriental de Chile, una "frontera natural" desde la época de la conquista española, sino sobre todo porque la precisa delimitación del país fue un asunto que lo ocupó. Esto no impidió que aprovechara el reconocimiento que hizo de ella para reafirmar lo que otros antes que él, como Poeppig, Darwin y Domeyko, habían señalado respecto de la potencia de la naturaleza reflejada en la elevación de los Andes, su composición y orografía.

En su relato alude constantemente a "la gran cadena andina", que aseguraba se extendía "en forma casi continua desde un océano helado al otro", alcanzando en Chile su elevación máxima, con ramificaciones que se desarrollaban en todas direcciones, "ocupando al menos dos tercios de la república". ${ }^{51}$ Una forma omnipresente, imposible de omitir cuando se alude a casi cualquier fenómeno natural en Chile, que Gilliss menciona casi en cada página de su obra, y a

$50 \mathrm{El}$ conocimiento acumulado hasta entonces fue aprovechado por el geógrafo Pedro Lucio Cuadra para la redacción de la memoria presentada a la Universidad en 1866 y publicada en 1868 en los Anales de la Universidad de Chile como "Apuntes sobre la geografía física y política de Chile".

${ }^{51}$ Gilliss, Expedición astronómica naval de los Estados Unidos, p. 31. 
la que obviamente accedió para examinar "las últimas líneas de formación estratificada”, las que, aseguró, a medida que se aproximan las cumbres más elevadas, "muestran la evidencia de las violentas revoluciones y terroríficos choques que han experimentado, como si la fuerza que expulsó estas inmensas masas de granito desde el fondo de la tierra hubieran concentrado su energía para hacerla llegar hasta la cumbre misma de las montañas". ${ }^{52}$ Reafirmando así el carácter de forma originada en las convulsiones internas de la tierra que, la ciencia aseguraba, exhibían en los Andes una expresión elocuente, además de muy asequible y por eso objeto de numerosas descripciones.

Aunque el astrónomo reconoció que hasta el momento de su estadía en Chile se había "obtenido muy poca información confiable sobre las cordilleras hacia el norte o el sur de las provincias centrales", supo aprovechar los reconocimientos existentes y ofreció una descripción general, que seguía muy de cerca la ofrecida por Domeyko. ${ }^{53}$ Desde el extremo norte escribió:

[...] la principal cadena de los Andes se eleva cada vez más hasta la latitud $35^{\circ}$; desde ahí hacia el sur el descenso de sus puntos

52 Gilliss, Expedición astronómica naval de los Estados Unidos, pp. 38-39.

${ }_{53}$ A pesar de la impresión de Gilliss, hasta mediados del siglo XIX algunos aventureros habían explorado los Andes en el sur, a la altura de las provincias de Valdivia y Llanquihue, es decir, entre los $39^{\circ}$ y $42^{\circ}$ de latitud sur aproximadamente, sobre todo en búsqueda de vías de comunicación trasandinas. Entre ellos, Aquinas Ried, Wilhelm Frick, Benjamín Muñoz Gamero, Francisco Fonck y Fernando Hess. Salvo el del comandante de la marina, Muñoz Gamero, fueron reconocimientos de escasa repercusión más allá del estrecho ámbito de la provincia. 
culminantes no es menos uniforme. Al centro de Chile está compuesta por dos cumbres elevadas y varias cadenas de montañas de menor altura. Al norte y al sur de este distrito varia el número de cordones y no hay menos de cinco cerca del paralelo de Talca. La dirección general coincide con un meridiano de longitud, aunque de las líneas menores algunas tienen inclinaciones N.O. y otras N.N.E., en tanto que los espolones laterales ocupan casi todos los puntos del compás”. ${ }^{54}$

Refiriendo sus fuentes de información, lo que hace posible identificar las formas de circulación del conocimiento, Gilliss alude a la que llama "inspección trigonométrica para el gobierno que el señor Pissis" estaba realizando, lo que le había permitido explorar desde los $32^{\circ} 20^{\prime}$ a los $34^{\circ}$ de latitud sur, reconociendo que el geógrafo francés "amistosamente me proporcionó una copia pequeña de su mapa”. ${ }^{55}$

Muy interesado en todo lo relacionado con los Andes, Gilliss también accedió a Ignacio Domeyko, “el único viajero científico que conozco que haya llegado a la cumbre de los Andes por algún otro paso cordillerano que no sea el de Portillo", y a su obra, que se transformó en fuente de información esencial, ${ }^{56}$ por ejemplo respecto de la ubicación de la línea divisoria de las aguas en diferentes zonas de la cordillera. ${ }^{57}$ Mientras que Darwin es también referencia respecto de los términos que utilizó para aludir a la montaña, “Andes” o "cordillera”, o a sus formas, "cadena principal”, “cadena montañosa”, "muchos cordones separados”,

${ }^{54}$ GiLliss, Expedición astronómica naval de los Estados Unidos, p. 31.

${ }^{55}$ Gilliss, Expedición astronómica naval de los Estados Unidos, p. 32.

${ }^{56}$ GiLliss, Expedición astronómica naval de los Estados Unidos, p. 38.

${ }^{57}$ GiLliss, Expedición astronómica naval de los Estados Unidos, p. 7. 
"estribaciones y cadenas externas de los Andes" y "serie de montañas" ${ }^{58}$ Corrigiéndolo afirmó que algunas de las más altas cumbres de la que Darwin consideró cadena principal de los Andes, "se encontraban al oeste de lo que exámenes más recientes demuestran que son sólo un espolón de la real línea divisoria de las aguas". ${ }^{59}$ Reflejando en su texto una realidad más adelante obviada, o tal vez aprovechada, esto es que las más altas cumbres no coincidían con la línea divisoria de las aguas, concluyó, a propósito de El Descabezado en la región del Maule: "Aquí, así como en muchos otros puntos de los Andes, los cerros que separan las aguas son invariablemente menos elevados que la línea que conectaría los grandes conos o picos". ${ }^{60}$

Gilliss afirmó que el límite oriental de Chile era la cordillera, sus máximas alturas, las que describió como "una línea imaginaria que pasa o atraviesa por las cumbres más altas de los Andes, que la separa de la República Argentina". ${ }^{61}$ Asentando, en razón de lo que en la época ya se discutía, que las líneas de las más altas cumbres y de la divisoria de las aguas eran dos, no una, siendo la demarcatoria principal la configurada por las más altas cumbres. Así lo afirmó en su obra cada vez que se refirió a los límites del país o a los de las provincias que lo conformaban, reflejando una ambigüedad conocida y asentada por los científicos. La que, sin embargo, y entre otras razones por la escala en que fue ejecutado,

58 Gilliss, Expedición astronómica naval de los Estados Unidos, pp. 370, 394 y 396.

${ }^{59}$ Gilliss, Expedición astronómica naval de los Estados Unidos, p. 19.

60 Gilliss, Expedición astronómica naval de los Estados Unidos, p. 23.

${ }^{61}$ Gilliss, Expedición astronómica naval de los Estados Unidos, pp. 44, 48 y 75 . 
Figura 5

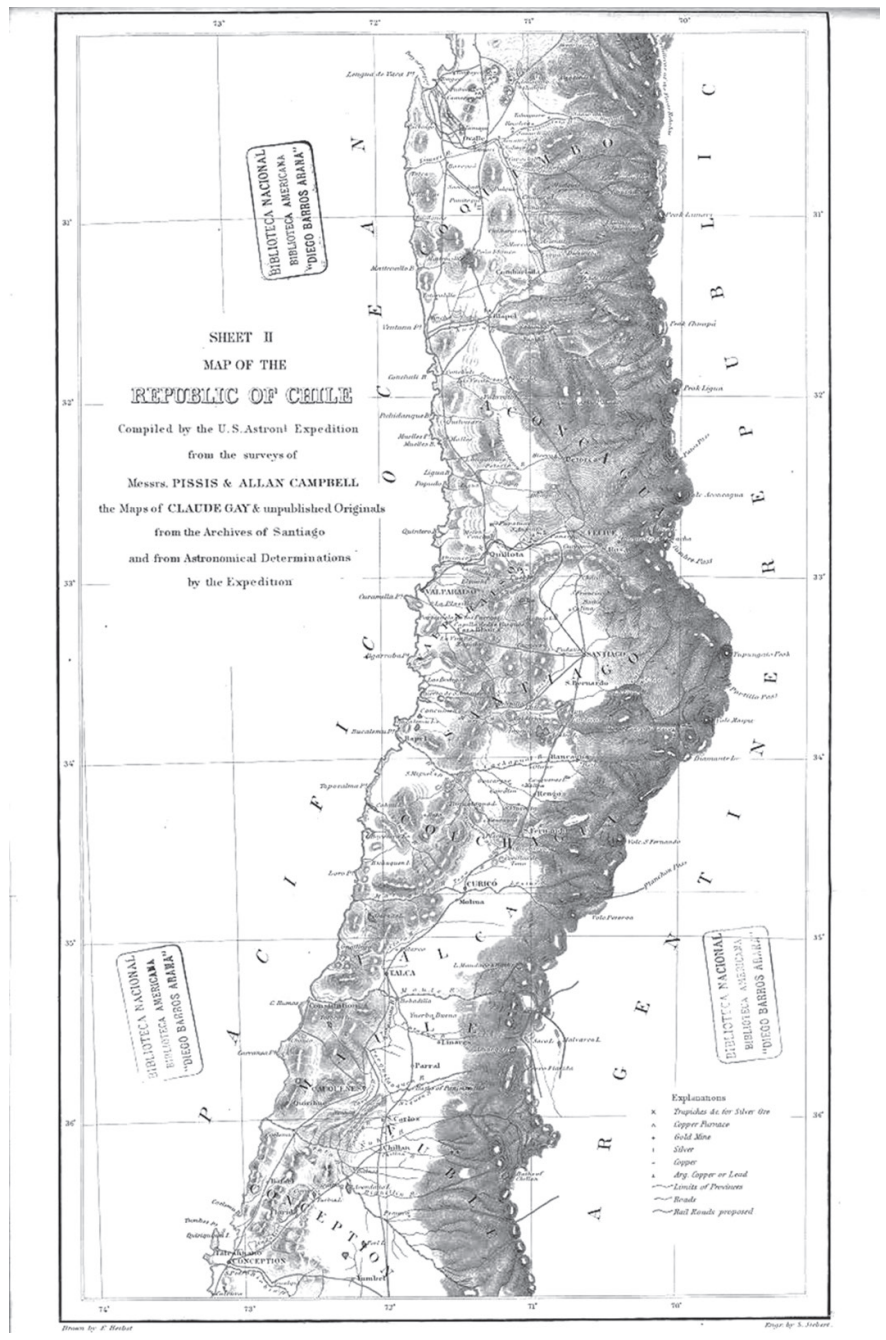

Sección del mapa de la República de Chile reproducido en el texto de Gilliss y preparado sobre la base de los trabajos de Gay, Pissis y Campbell. 
no se distingue en el mapa de Chile que incluyó en su obra, el cual fue elaborado sobre los trabajos de agrimensura de Pissis, los del ingeniero de ferrocarriles estadounidense Allan Campbell, la cartografía de Claudio Gay y las mediciones del propio Gilliss y su expedición astronómica.

Tal vez la incertidumbre que la realidad descrita por Domeyko y otros sembró explica que cuando el gobierno contrató en 1848 al geógrafo y geólogo francés Amado Pissis para "hacer una descripción geológica y mineralógica de la república”, que incluyó la comisión de levantar un mapa científico de Chile, se estableciera claramente que "dedicará una particular atención a la cordillera de los Andes, que examinará del modo más prolijo que le sea posible”, todo con el "fin de señalar con precisión el filo o línea más culminante que separa las vertientes que se van a las Provincias Argentinas de las que se dirigen a territorio chileno". ${ }^{62}$

Ya en 1850, en los primeros avances de su trabajo, el geógrafo escribió que como su plan era describir el relieve, la dirección, extensión y altura de las cadenas de montañas, ya estaba preparando "una carta geológica" en la que pudiera hallarse "todo lo relativo a la configuración del terreno", para lo cual estaba empleando métodos geodésicos y astronómicos. Fruto de su quehacer, en 1852 publicó sus investigaciones sobre la altitud de los cerros culminantes de la cordillera de los Andes, y desde entonces las descripciones topográficas y geológicas de provincias del país, como las de Valparaíso (1854) y el Aconcagua (1858), las que, junto con

${ }^{62}$ Véase el art. $1^{\circ}$ del contrato suscrito entre el geógrafo y el ministro del Interior en la obra de Pissis, Geografía física de la República de Chile, p. xii. 
otros textos también publicados en los Anales de la Universidad de Chile, terminarían formando parte de su Geografía física de la República de Chile aparecida en 1875. Obra que incluye dos trabajos cartográficos, el "Plano topográfico y geológico de la República de Chile”, escala 1:250000, y el "Mapa de la República de Chile desde el río Loa hasta el Cabo de Hornos", escala 1:1000000. Publicados en 1873 y 1888 , respectivamente.

El trabajo de Pissis, además de la detallada representación del relieve cordillerano, ofrece una minuciosa descripción orográfica de cada uno de los llamados macizos, o cumbres, que destacan en cada uno de los tramos de cordillera explorados por el geógrafo, completando así, ahora, además, por medio de un texto, la representación del relieve cordillerano que Gay había realizado en su mapa de 1841. De este modo quedó configurada por la ciencia la cadena montañosa que Pissis llamó "cordillera de Chile", confirmado su extenso desarrollo latitudinal, identificadas su composición geológica y estructura orográfica, y advertida la variedad de formas que ofrecía. Sin perjuicio de que prácticamente todos quienes la describieron, estudiaron y exploraron, señalaron su condición demarcadora, de "obstáculo natural", entre regiones geográficamente diferenciadas como lo son sus vertientes oriental y occidental..$^{63}$ Realidad que el botánico de origen alemán, Rodulfo Amando Philippi, avecindado

${ }^{63}$ De la idea de frontera natural, con el siglo y las polémicas limítrofes, en la segunda mitad del siglo XIX se pasará a la idea de los Andes como barrera, línea, frontera política. Un ejemplo de lo ocurrido puede apreciarse en el trabajo de NúñEz, "La frontera no deja ver la montaña: invisibilización de la cordillera de Los Andes en la Norpatagonia chilenoargentina”. 
en Chile desde 1851, graficó de forma elocuente y sencilla en su trabajo comparativo de la flora y la fauna de Chile y Argentina.

En él asentó que, si bien se podría creer que ambos países deberían tener similares plantas y animales por estar en la misma latitud, lo cierto es que no era así, en lo esencial, por la existencia de la cordillera de los Andes. Así, por ejemplo, y a propósito del régimen de lluvias en una y otra vertiente, Philippi afirmó que "la cordillera es una verdadera línea divisoria de las lluvias", y que si por un momento se suponía que no existiese entre Chile y Argentina, "es claro que entonces no habría contraste alguno entre las regiones occidentales y orientales". ${ }^{64}$

El ejercicio que Philippi ideó para explicar el papel fundamental de los Andes como factor de la historia natural en América del Sur no era original y remite al realizado por Alexander von Humboldt a mediados del siglo xIx, cuando en 1845 inició la publicación de su Cosmos. Ensayo de una descripción física del mundo. En él, en la sección destinada a la Tierra y sus fenómenos, entre ellos la formación de los continentes y su "figura actual", alude al papel que tienen "los levantamientos de las cadenas de montañas", especulando sobre "¡cuán diferente de cómo es hoy no habría sido la temperatura de la Tierra, la vegetación, la agricultura y hasta la civilización misma, si los ejes del antiguo y del nuevo continente hubieren recibido igual dirección; si la cadena de los Andes, en vez de dibujar un meridiano, corriese del este al oeste" ${ }^{65}$ Ilustra de este modo el papel de la cordillera

64 Philippi, “Comparación de las floras i faunas”, p. 539.

65 Humboldt, Cosmos, p. 158. Antes todavía, Darwin, asentó en su relato 
americana en la configuración del planeta, uno de los problemas que lo ocupó y que proyectó a los Andes como elemento básico de la historia natural de la Tierra, entre otros factores, gracias al conocimiento generado por los científicos en Chile.

\section{LOS ANDES ARGENTINOS}

A mediados del siglo xix comenzó en el Río de la Plata la exploración sistemática de la actual Argentina, la que por sus objetivos, medios y condiciones, por ejemplo su afán por conocer América Meridional en general, independientemente de fenómenos naturales específicos, se distingue de la de los viajeros que hasta entonces habían recorrido los que una autora llama "Andes argentino-chilenos". ${ }^{66}$ En su relación de la orografía de la Confederación Argentina, incluida en su Descripción geográfica y estadística publicada en 1860, luego de recorrer entre 1855 y 1858 todo el territorio del Estado que lo contrató para realizar un "trabajo descriptivo y estadístico general”, el naturalista francés, V. Martin de Moussy, ofrece una detallada descripción de los que, por los objetivos de su trabajo, llama "Andes argentinos", nacionalizando así una forma natural representada por muchos

que "no deja de chocarme la gran diferencia que hay entre la vegetación de estos valles orientales -en Argentina- y la de Chile, porque el clima y la naturaleza del suelo son casi idénticos y la diferencia de longitud insignificante". Atribuyendo a los Andes, "barrera infranqueable", la realidad que describía. Véase Darwin, Viaje de un naturalista, p. 304.

${ }^{66}$ Véase la monografía de Hevilla, "Los viajeros de las alturas", en la cual, utilizando como fuente una selección de escritos de viajeros que cruzaron la cordillera a lo largo del siglo xIx, ofrece una interpretación sobre la calidad de productores de imágenes para la cultura europea de los textos de estos, más de uno, espontáneos aventureros. 
viajeros como amenazante, ajena y hostil. ${ }^{67}$ Para Martín de Moussy, también parte de un sistema montañoso compuesto por otros tres grupos perfectamente caracterizados que interrumpían o flanqueaban el paisaje esencial del suelo argentino: "una llanura absoluta". ${ }^{68}$

Si por su extensión la pampa comprendía prácticamente todo el vasto territorio considerado argentino a mediados del siglo XIX, siendo el principal objeto de preocupación de los científicos que como Martín de Moussy y Germán Burmeister lo recorrieron, no por ello el macizo andino está ausente de sus relaciones, básicamente como frontera con Chile y límite de las llanuras. La que Martín de Moussy llama "región andina" es descrita como "un gigantesco cordón, aterrador por la altura y la extensión de sus aglomeraciones", con una inclinación suave en sus faldas orientales, mientras que las occidentales se presentan abruptas y precipitándose al Pacífico. Se aleja así de la descripción que Darwin había ofrecido para el mismo fenómeno: "la vertiente oriental de la cordillera está mucho más en pendiente que la que mira al Pacífico; o en otros términos, son más abruptas las montañas que se elevan sobre las llanuras que las que dominan la región ya montañosa de Chile”. ${ }^{69}$ Nuevo ejemplo de que las formas geográficas y la naturaleza son dinámicas y flexibles, y serán lo que el punto de vista del observador valore y describa.

Apreciados como barrera natural divisoria, los Andes, en la representación de una sociedad que se desenvolvía en el

\footnotetext{
${ }^{67}$ Véase Hevilla, "Los viajeros de las alturas", pp. 71-76.

${ }_{68}$ Martin de Moussy, Descripción geográfica, I, p. 243.

${ }_{69}$ Darwin, Viaje de un naturalista, p. 304.
} 
llano, aparecen en ocasiones abruptos, bruscos, de pendientes rápidas, "una muralla muy elevada de color negruzco". ${ }^{70}$ Mientras que en otras, ahora por su aspecto general, más amables: "vistos del lado de las pampas, aparece la sierra como una corrida de alturas divididas en pocas cumbres gibosas parecidas entre sí, extendidas de norte a sur con alturas casi iguales, de las que se desprenden hacia la planicie ramales separados por quebradas angostas y tortuosas". ${ }^{71}$

Andes que sin perjuicio de las disímiles representaciones que motivan, incluso apreciados desde la misma perspectiva, en la obra de Martín de Moussy, y citando a los científicos que, como Gay, Darwin, Domeyko y Pissis los habían estudiado, merecen una detallada descripción en lo que dice relación con su extensión, formas, aspecto, composición geológica y elementos como glaciares, mesetas, volcanes y yacimientos metalíferos. Con particular atención, a pesar de su concepción como muralla, a los pasos cordilleranos, que se identifican y describen, incluyendo longitud, condiciones, características y usos, los que se presentan como vías de comunicación que permiten concluir al naturalista que no por alta y ancha que sea la "poderosa barrera, lo cierto es que atravesarla es menos difícil de lo que se cree". ${ }^{72}$

Los rasgos generales de los Andes que Martín de Moussy ofrece en la geografía de Argentina se reiteran y precisan cuando aborda la descripción particular de cada una de las provincias que tienen como límite occidental la cordillera, como San Juan y Mendoza, oportunidad en la que el macizo

70 Martin de Moussy, Descripción geográfica, I, pp. 189-191.

71 Burmeister, Viaje por los estados del Plata, I, p. 257.

72 Martin de Moussy, Descripción geográfica, I, pp. 195-214. 
se revela como frontera formada por gigantescos nevados que erizan sus crestas. Características que, sin embargo, no se aprecian en la cartografía que el científico levantó y publicó en 1867 como "Carta de la Confederación Argentina dividida en sus diferentes provincias y territorios. Y de los países vecinos. Estado Oriental del Uruguay. Paraguay. Parte de Brasil y de la Bolivia. Chile”. Y en la cual la cordillera aparece representada casi exclusivamente como parte del territorio chileno, coincidiendo así con las visiones planetarias existentes sobre el relieve de la Tierra que la muestran prácticamente sobre el océano Pacífico.

\section{LOS ANDES, RELIEVE PLANETARIO}

Desbordando el acotado marco de la investigación local, el conocimiento acumulado sobre América Meridional en general, y los Andes en particular, sirvió para alimentar y fundar obras de alcance general sobre el planeta, como la desarrollada por Humboldt. Se transformó así en un ejemplo de saber parcial para la ciencia universal que, al traspasar las fronteras nacionales, ofrece una nueva perspectiva de los Andes, en la cual ésta aparece representada como una realidad natural planetaria indispensable de atender por los fenómenos que, a través de ella, o por su influencia, se manifiestan en la Tierra.

Para Humboldt Chile era un territorio lejano y limítrofe; un espacio utilizado para indicar los márgenes de América, el fin de la masa continental hacia el sur. Indicio de otra característica en la obra humboldtiana, su estrecha relación con la cordillera, y por lo tanto su frecuente aparición cuando el naturalista alude a paisajes montañosos. Lo que a su 
vez da paso a su mención cuando se trata de referir a fenómenos volcánicos y telúricos. Configurándose así una realidad geográfica, la chilena y andina, signada por fenómenos naturales extremos.

La cordillera es el fenómeno natural más relacionado con América Meridional en la obra de Humboldt. Temprano en sus escritos aparece como un elemento propio de este territorio, tanto como para hablar de "las cordilleras de Perú y Chile", o de "las cordilleras occidentales de Chile", como lo hace en sus Cuadros de la naturaleza. Al sabio le interesan las características del relieve del planeta, entre las que se cuentan las montañas, las que en el caso del continente americano, refiere con detalle, se prolongan "desde las rocas de granito de Diego Ramírez y las costas profundamente escotadas de la Tierra del Fuego, hasta el océano Glacial Ártico", advirtiendo que "tienen estas cordilleras una extensión de 1500 miriámetros aproximadamente". ${ }^{73}$ Aludiendo a la obra de Charles Darwin, Humboldt explica que "lo que llamamos una cadena de montañas no se alzó todo de un golpe y no se produjo al exterior de un modo repentino", sino que es fruto de la superposición de rocas de muy diversa edad; tal y como el científico inglés lo había apreciado durante su viaje en el Beagle y, después, explicado detenidamente en su texto Observaciones geológicas en América del Sur. De hecho, el viaje comandado por Robert Fitz-Roy es una valiosa fuente sobre la geografía americana que el naturalista prusiano utiliza con frecuencia para fundar su visión totalizadora, la cual reúne elementos y fenómenos hasta entonces dispersos.

${ }^{73}$ Humboldt, Cuadros de la naturaleza, pp. 69, 75 y 79. 
La extensión y características de las cordilleras existentes en el margen occidental de América que, advierte Humboldt en sus Cuadros de la naturaleza, "no son las más altas, pero sí las más largas de todas las cadenas de montañas”, le permitirán describirlas más tarde en su Cosmos como un "inmenso baluarte natural que se extiende desde Chile meridional hasta la costa noroeste de América" ${ }^{74}$ Forma que se representa reiteradamente en los mapas geológicos que forman parte del Physikalischer Atlas, que Heinrich Berghaus publicó entre 1845 y 1848, y que originalmente fue concebido, de acuerdo con Humboldt, como complemento cartográfico de Cosmos. ${ }^{75}$ Lo que explica que en algunos mapas una leyenda particular refiera a aquellas partes de la obra del sabio prusiano en que se alude al tema que se ilustra por medio del mapa.

$\mathrm{Su}$ interés en la cordillera, que alternativamente se grafica como Andes de Chile, Andes de Bolivia, Andes de Perú y Andes de Quito en el Atlas de Berghaus, se explica también porque para Humboldt "la cadena de los Andes nos ofrece en gran escala el ejemplo de una cadena volcánica, colocada en tierra firme", aludiendo así al otro fenómeno naturalmente asociado a los Andes, los volcanes. Como el Osorno, Antuco, Corcovado, Chillán y Maipo, entre otros; los que llama "grupo de Chile" o "volcanes de Chile", que

${ }^{74}$ Es sabido que Humboldt recorrió y exploró los Andes entre Caracas y Lima, dejando numerosos textos, mapas y representaciones de esa sección de la cordillera. De los Andes meridionales escribió y los representó a partir de los trabajos de otros naturalistas, los que cita reiteradamente. ${ }^{75} \mathrm{El}$ atlas ofrece ilustraciones de los principales fenómenos de la naturaleza orgánica e inorgánica representados de acuerdo con su distribución geográfica en el plantea. 
conforman una "de las regiones, junto a Centroamérica, donde están reunidos en menor espacio mayor número de volcanes, los más todavía activos”, advierte. Todos ellos, a su vez, formando parte de un inmenso perímetro que incluye Nueva Zelandia, Nueva Guinea, las Filipinas, Asia oriental, América, México y América Central hasta la extremidad de Chile, hoy conocido como "cinturón de fuego del Pacífico”, y que según Humboldt alcanzaba 6600 millas geográficas de actividad volcánica. ${ }^{76}$ Fenómeno que aparece representado también en el Atlas de Berghaus en la llamada Karte von dem vulkan gürtel und den central gruppen des grossen oceans. ${ }^{77}$

Particular mención merece en su obra el volcán Antuco, "en la parte de la cordillera de los Andes del sur de Chile, en la latitud $37^{\circ} 7^{\prime}$ sur, prácticamente en frente de Talcahuano”, respecto del cual ofrece amplia información sobre sus características, altitud, tipo de erupciones, torrentes de lava y otras especificaciones fruto de un acabado conocimiento del mismo. La atención se explica por lo asequible que resultaba éste para los estudiosos, y por lo tanto los numerosos trabajos que le sirven de fuente a Humboldt, y que el sabio cita ampliamente. Eduard Poeppig, Ignacio Domeyko, el marino y astrónomo estadounidense James M. Gilliss, el viajero inglés E. R. Smith, Charles Darwin, Robert Fitz-Roy, Claudio Gay y Amado Pissis son los más referidos. ${ }^{78}$

76 Humboldt, Cosmos, pp. 148, 776, 777, 784, 794, 796, 799, 823, 832, $853,862,890$ y 903 .

77 Véase Berghans, Physikalischer Atlas, pp. 76-77. El mapa muestra el cinturón volcánico y el grupo volcánico central de los grandes océanos. 78 Humboldt, Cosmos, pp. 777, 796, 890 y 909. El ingeniero Alan Campbell también es citado por sus mapas. 
A Fitz-Roy y Darwin atribuye "el primer impulso que se dio al conocimiento geográfico del grupo volcánico de Chile"; a Philippi, aludiendo a su texto Viaje al desierto de Atacama, lo caracteriza como "muy familiarizado con esta comarca", y por tanto confiable en su información; de Pissis ocupa las latitudes y longitudes que el geólogo ofrece en sus mapas de los fenómenos naturales de Chile, pero también sus monografías publicadas en los Anales de la Universidad de Chile con la altitud de las crestas, algunas volcánicas, de los Andes; lo mismo con los mapas y cálculos obtenidos por Gilliss durante su expedición en Chile, pero también con los mapas que reproduce en su obra; del abate Molina cita la información histórica que su obra refiere sobre erupciones volcánicas; de Claudio Gay e Ignacio Domeyko sus trabajos describiendo sus ascensiones a diferentes volcanes; y su compatriota Poeppig le proporciona cuidadas descripciones geológicas de los volcanes, como también elocuentes testimonios de erupciones recientes. Así, Humboldt dispuso de información muy actualizada, pues la mayor parte de los citados, salvo Molina, recorrió Chile durante la primera mitad del siglo xIx. Incluso puede citar el relato de Gilliss y los cálculos de Pissis, que datan de 1854. A la mayor parte de los nombrados los llama "autoridades", entre otras razones por su conocimiento directo de los fenómenos que describen, y todos ellos son los que le permiten afirmar que en Chile había a lo menos trece volcanes activos. ${ }^{79}$

${ }^{79}$ Humboldt, Cosmos, pp. 796, 797, 799 у 800. 
Figura 6

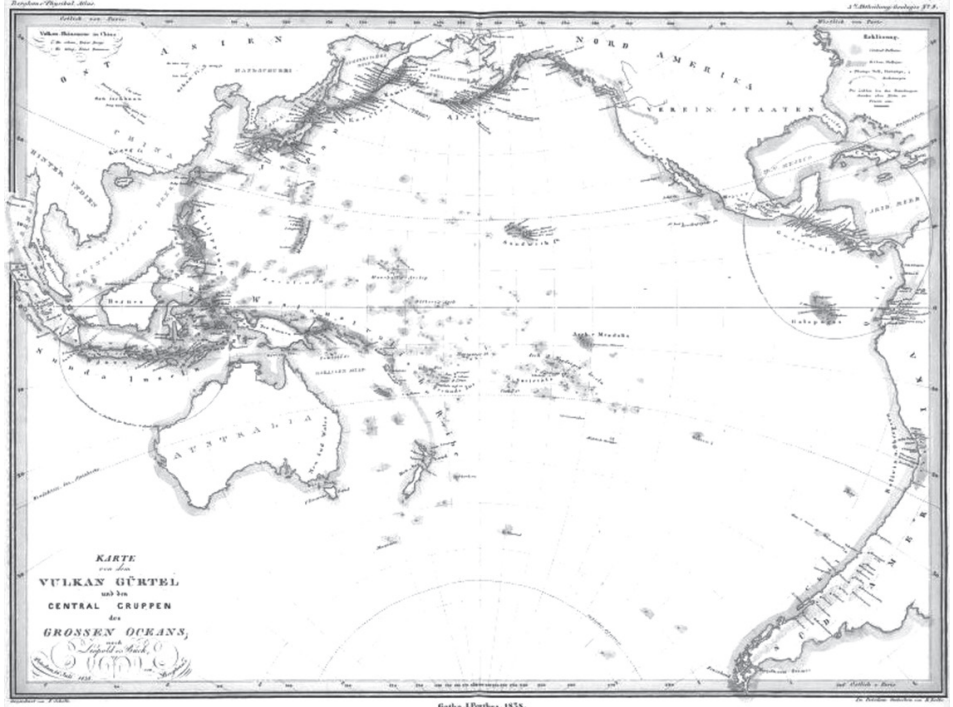

Heinrich Berghaus, "Karte von dem vulkan gürtel und den central gruppen des grossen oceans", en Physikalischer Atlas.

Interesado en la descripción física del mundo y en los factores que la condicionan, atento a la conformación geológica del planeta y a los fenómenos que modelan el relieve, o explican los diversos ambientes e inciden en la distribución de los seres vivos, Humboldt aprovechó las noticias, el saber que diferentes naturalistas acumularon sobre la cordillera de los Andes en tanto realidad particular y local, para representarla como un fenómeno natural de alcance global. Para proyectarla como expresión de la magnitud y forma de la Tierra, como escenario de las manifestaciones internas del planeta. Como una cadena montañosa que, atento 
a lo que consultó, no pudo dejar de reconocer, ahora volviendo a la escala local, "como cordilleras divididas en dos y tres hileras, lo cual por otra parte, afirmó, está conforme con la expresión española de las cordilleras de los Andes". ${ }^{80}$

Asentada de este modo una realidad que no sólo devolvió a los Andes meridionales a su entorno y situación original, el extremo sur de América, entre Chile y Argentina; también a su condición de fenómeno multiforme, flexible según la escala y perspectiva con que se analiza, imposible de definir como una sola y uniforme figura geográfica. En especial si se exploraba y describía desde la perspectiva de los intereses nacionales, las reivindicaciones territoriales y soberanas, en medio de querellas limítrofes, como ocurriría entre Chile y Argentina desde mediados del siglo XIX en adelante, cuando comenzó su disputa por los Andes, y la ciencia adquirió nacionalidad, la cordillera se transformó en motivo de controversia política y científica y dejó de ser estudiada sólo como un paisaje natural. ${ }^{81}$

\section{REFERENCIAS}

Berghaus, Heinrich, Physikalischer Atlas: oder Sammlung von Karten, auf denen die hauptsächlichsten Erscheinungen der anorganischen und organischen Natur nach ibrer geographischen Verbreitung und Vertheilung bildlich dargestellt sind. Zu Alexander von Humboldt, Kosmos. Entwurf einer physischen Weltbeschreibung, Fráncfort del Mano, Eichborn Verlag, 2004 [1 $1^{\text {a }}$ ed. en alemán, 1845-1848].

80 Humboldt, Cosmos, p. 857.

81 En la monografía "Territorio y saber en disputa. La controversia limítrofe chileno-argentina sobre los Andes”, ofrecemos un ejemplo del uso del saber geográfico en función de las reivindicaciones de soberanías territoriales. 
Burmeister, Germán, Viaje por los estados del Plata, Buenos Aires, Academia Nacional de la Historia y Unión Académique Internationale, 2008 [1 $1^{a}$ ed. en alemán, 1861].

Cuadra, Pedro Lucio, "Jeografía física i política de Chile. (Apuntes sobre la)", en Anales de la Universidad de Chile, 30 (2) (febrero 1868), pp. 61-226.

DARWIN, Charles, Viaje de un naturalista alrededor del mundo, Madrid, Miraguano Ediciones, 1998 [1 $1^{\mathrm{a}}$ ed. en inglés, 1839].

DARwin, Charles, Observaciones geológicas en América del Sur, Madrid, Consejo Superior de Investigaciones Científicas, Dirección de Bibliotecas, Archivos y Museos, Universidad Autónoma de México, Los Libros de la Catarata y Editorial Universitaria, 2011 [1 $1^{\text {a }}$ ed. en inglés, 1846].

Diener, Pablo, La obra de Juan Mauricio Rugendas. Ilustrando su viaje a través de Chile. 1834-1842, Santiago, Origo Ediciones, 2012.

Dомеyко, Ignacio, Excursión a las cordilleras de Copiapó. Con una breve exposición de los principios fundamentales de la jeología de Chile, Santiago, Imprenta del Estado, 1843.

Dомеүко, Ignacio, Jeografía jeológica. Estudio del relieve o configuración exterior del territorio chileno con relación a la naturaleza jeológica de los terrenos que entran en su composición, en Estudios jeográficos sobre Chile. Memorias relativas a varias cuestiones sometidas al Congreso Internacional de Ciencias Jeográficas de París de 1875, Santiago, Imprenta Nacional, 1875, pp. 47-81.

Domeyкo, Ignacio, Mis viajes. Memorias de un exiliado, Santiago, Ediciones de la Universidad de Chile, 1979.

Dомеyкo, Ignacio, "Viaje a las cordilleras de Talca i de Chillán", en Anales de la Universidad de Chile (1849), pp. 7-64.

Dомеyкo, Ignacio y Wenceslao Díaz, "Excursión jeológica a las cordilleras de San Fernando, hecha en el mes de febrero de 1861", en Anales de la Universidad de Chile (ene. 1862), pp. 22-42. 
Espinoza, José y Felipe Bauzá, "Observaciones de la velocidad del sonido, de latitud, longitud y variación hechas en Santiago de Chile por el Teniente de Navío Don Josef de Espinosa y el Alférez de Navío Don Felipe Bauzá en 1794", en Memorias sobre las observaciones astronómicas hechas por los navegantes españoles en distintos lugares del globo; las quales han servido de fundamento para la formación de las cartas de marear publicadas por la Dirección de Trabajos Hidrográficos de Madrid. Ordenadas por Don Josef Espinosa y Tello, t. I, Madrid, Imprenta Real, 1809, pp. 169-182.

Feliú Cruz, Guillermo y Carlos Stuardo Ortiz, Correspondencia de Claudio Gay, Santiago, Ediciones de la Biblioteca Nacional, 1962.

Gay, Claudio, Atlas de la historia física y política de Chile, Santiago, LOM Ediciones, 2004.

Gilliss, James M., Expedición astronómica naval de los Estados Unidos al hemisferio sur durante los años 1849, 50, 51 y 52, Santiago, Septiembre Ediciones y Dirección de Bibliotecas, Archivos y Museos, 2016 [1 ed. en inglés, 1855].

Hevilla, Cristina, "Los viajeros de las alturas: narrativas de viajeros y científicos sobre Los Andes argentino-chilenos", en Zusman, Lois y Castro (comps.), 2007, pp. 67-92.

Humboldt, Alexander von, Cuadros de la naturaleza, Madrid, Los Libros de la Catarata, 2003 [1ª ed. en alemán, 1808-1849].

Humboldt, Alexander von, Cosmos. Ensayo de una descripción física del mundo, Madrid, Consejo Superior de Investigaciones Científicas, Dirección de Bibliotecas, Archivos y Museos y Los Libros de la Catarata, 2011 [1ª ed. en alemán, 1845-1862].

Martin de Moussy, V., Descripción geográfica y estadística de la Confederación Argentina, Buenos Aires, Academia Nacional de la Historia, 2005 [1 $1^{\mathrm{a}}$ ed. en francés, 1860].

NúñEz, Andrés, "La frontera no deja ver la montaña: invisibilización de la cordillera de Los Andes en la Norpatagonia chileno-argentina", en Revista de Geografía Norte Grande, 55 (2013), pp. 89-108. 
Philippi, R. A., "Comparación de las floras i faunas de las repúblicas de Chile i Argentina”, en Anales de la Universidad de Chile (1893), pp. 529-555.

Pissis, A., Geografía física de la república de Chile, Santiago, Pontificia Universidad Católica de Chile, Dirección de Bibliotecas, Archivos y Museos, Cámara Chilena de la Construcción, 2011 [1ª ed., París, 1875].

Poeppig, Eduard, Un testigo en la alborada de Chile (1826-1829), Santiago, Zig-Zag, 1960 [1ª ed. en alemán, 1835].

SAGRedo BAeza, Rafael, "El Atlas de Gay y la obsesión por representar Chile”, 2004, pp. 9-55.

SAgRedo Baeza, Rafael, “Territorio y saber en disputa. La controversia limítrofe chileno-argentina sobre los Andes", en Asclepio, 68 (2) (juliodic. 2016), pp. 1-16.

SAgredo Baeza, Rafael y José Ignacio González Leiva, La Expedición Malaspina en la frontera austral del imperio español, Santiago, Editorial Universitaria y Dirección de Bibliotecas, Archivos y Museos, 2004.

Stuardo Ortiz, Carlos, Vida de Clandio Gay. 1800-1873. Seguida de los escritos del naturalista e historiador, de otros concernientes a su labor y de diversos documentos relativos a su persona, Santiago, Nascimento, 1973.

Vega, Alejandra, Los Andes y el territorio de Chile en el siglo XVI. Descripción, reconocimiento e invención, Santiago, Dirección de Bibliotecas, Archivos y Museos, 2014.

Zusman, Perla, Carla Lois y Hortensia Castro (comps.), Viajes y geografías. Exploraciones, turismo y migraciones en la construcción de lugares, Buenos Aires, Prometeo Libros, 2007. 